\title{
Student Interview and Preference Assessment as Functional Behavior Assessment Tools in Schools
}

\author{
Gabrielle Mesches
}

Follow this and additional works at: https://researchrepository.wvu.edu/etd

\section{Recommended Citation}

Mesches, Gabrielle, "Student Interview and Preference Assessment as Functional Behavior Assessment Tools in Schools" (2017). Graduate Theses, Dissertations, and Problem Reports. 6223.

https://researchrepository.wvu.edu/etd/6223

This Thesis is protected by copyright and/or related rights. It has been brought to you by the The Research Repository @ WVU with permission from the rights-holder(s). You are free to use this Thesis in any way that is permitted by the copyright and related rights legislation that applies to your use. For other uses you must obtain permission from the rights-holder(s) directly, unless additional rights are indicated by a Creative Commons license in the record and/ or on the work itself. This Thesis has been accepted for inclusion in WVU Graduate Theses, Dissertations, and Problem Reports collection by an authorized administrator of The Research Repository @ WVU. For more information, please contact researchrepository@mail.wvu.edu. 
Student Interview and Preference Assessment as Functional Behavior Assessment Tools in Schools

\section{Gabrielle Mesches}

Thesis submitted to the Eberly College of Arts and Sciences at West Virginia University in partial fulfillment of the requirements for the degree of

Master of Science in

Psychology

Claire St. Peter, Ph.D., Chair

Steven Kinsey, Ph.D.

Jennifer Austin, Ph.D.

Department of Psychology

Morgantown, West Virginia

2017

Keywords: Functional Behavior Assessment; Functional Analysis; Problem Behavior; Schools

Copyright 2017 Gabrielle Mesches 


\section{Abstract \\ Student Interview and Preference Assessment as Functional Behavior Assessment Tools in Schools}

Gabrielle Mesches

Functional behavior assessments (FBA) identify the consequences that maintain challenging behavior. Much of the current literature suggests that functional analyses are the most effective component of an FBA. However, functional analyses are most commonly used with children with developmental and intellectual disabilities. For children with complex verbal repertoires, other types of assessment may identify consequences maintaining behavior that can be subsequently manipulated as part of a classroom-based intervention. In the current study, we compared a student-completed interview and preference assessment to the outcomes of a functional analysis, and used the outcomes of all three assessments to evaluate classroom-based interventions to reduce challenging behavior. Conclusive assessment outcomes aligned for three of four target responses and interventions based on outcomes suppressed target responding for two of three students, indicating that students can identify functions of their own behavior during student-informed indirect assessments. 


\section{Table of Contents}

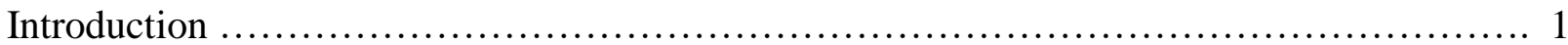

Experiment 1

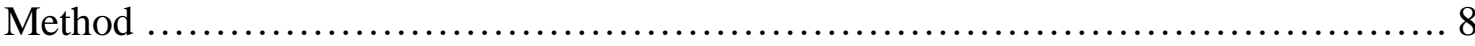

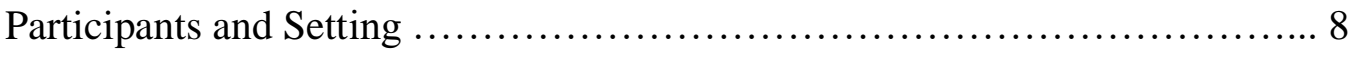

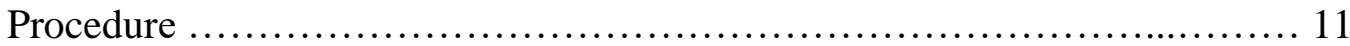

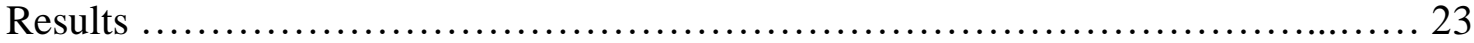

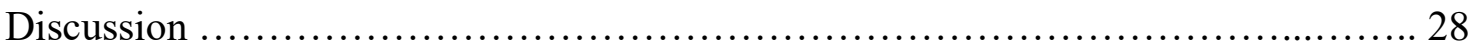

Experiment 2

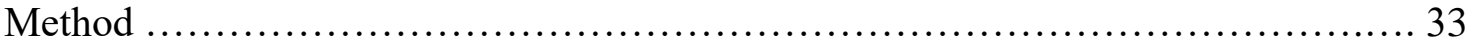

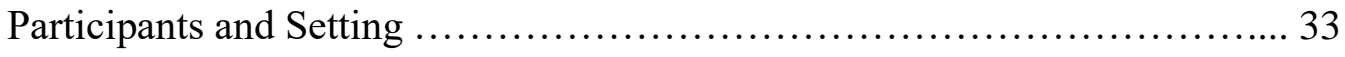

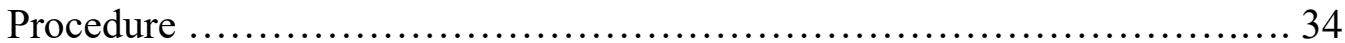

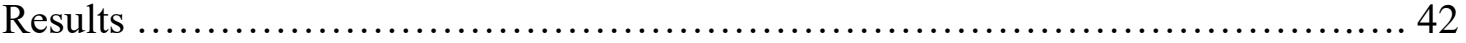

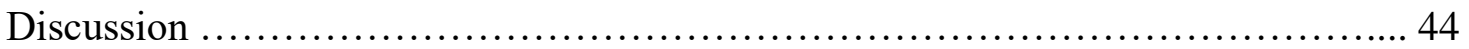

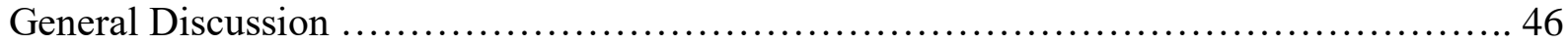

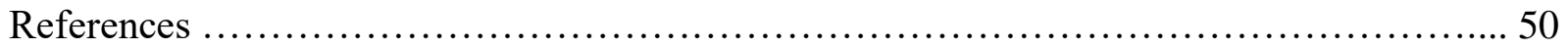

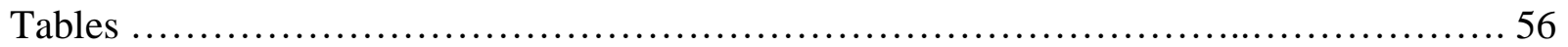

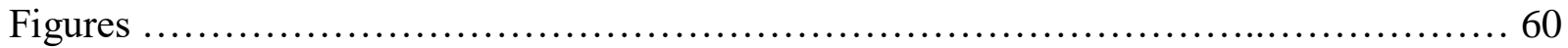

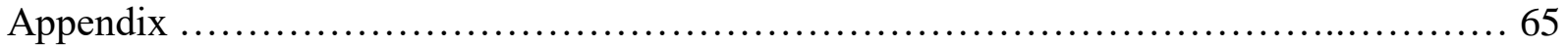




\section{Student Interview and Preference Assessment as Functional Behavior Assessment Tools in Schools}

Problem behavior may occur because of the environmental consequences produced by the behavior (Iwata, Kahng, Wallace, \& Lindberg, 2000). Thus, it may be possible to identify functional relations between behavior and environmental causes. Once these functional relations are identified, the environment can be changed to reduce problem behavior (Iwata, Dorsey, Slifer, Bauman, \& Richman, 1994; Hanley, Iwata, \& McCord, 2003). Functional behavior assessments (FBA) are widely used in schools to identify reinforcers maintaining problem behavior. Those reinforcers are then used to teach and maintain an appropriate alternative behavior. The use of FBA is mandated by the Individuals with Disabilities Education Act (IDEA, 1997) in some cases in which problem behavior disrupts the learning of the student or peers (Drasgow \& Yell, 2001).

There are many ways to conduct an FBA. One approach is to use a hierarchical model in which practitioners start with the least rigorous and least time-consuming procedures and progress to more rigorous procedures that require additional time and training as needed (Hanley, 2012). For example, Hanley (2012) defines the key components of a hierarchical model of an FBA as indirect assessment, descriptive assessment, and functional analysis. An indirect assessment measures behavior through interviews and rating scales (Paclawskyj, Matson, Rush, Smalls, \& Vollmer, 2000). A descriptive assessment involves observing the behavior in the natural environment (Vollmer, Borrero, Wright, Van Camp, \& Lalli, 2001; Lalli, Browder, Mace, \& Brown, 1993). A functional analysis requires the manipulation of antecedents or consequences surrounding a problem behavior to identify the variables maintaining the behavior (e.g., Iwata et al., 1994). The assumption with the hierarchical model is that conducting an FBA 
by progressing from interviews to manipulation of the environment will reveal the most accurate results.

Although the hierarchical model may be an effective method for completing an FBA, every step may not be required. Indirect assessments notoriously have poor reliability and validity, leading many authors to recommend that those assessments not be used in isolation to identify behavioral function (Hanley, 2012; Iwata, DeLeon, \& Roscoe, 2013). Descriptive assessments may lead to invalid findings, can take an excessive amount of time, and often yield inconclusive results (Hanley, 2012). Because of these shortcomings of other methods, the functional analysis still plays an essential role in an FBA. Functional analyses may be the most effective FBA component for guiding the development of behavioral interventions (e.g., Iwata et al., 1994; Iwata, Pace, Kalsher, Cowdery, \& Cataldo, 1990; Meyer, 1999).

Most functional analyses compare one or more test conditions to a control condition. During typical test conditions of functional analyses, potential reinforcers are withheld until the client engages in challenging behavior; the potential reinforcer is delivered if and only if challenging behavior occurs. For example, in an attention test condition, the therapist withholds attention until the client engages in the targeted challenging behavior, after which the therapist attends, often providing a brief reprimand or comforting statement and pat on the back. Rates of challenging behavior during test conditions are compared to rates during a control condition, during which the potential reinforcer is freely available. Elevated rates of a target behavior during a test condition above the rates during the control condition demonstrate that the event manipulated in that session functions as a reinforcer. Common test conditions include those for social-positive reinforcement (e.g., attention or tangible items such as food or activities), socialnegative reinforcement (e.g., escape from demands), and automatic reinforcement (e.g., behavior 
that persists in the absence of social contingencies). Most published functional analyses include at least two test conditions and a control condition (e.g., Beavers, Iwata, \& Lerman, 2013).

Published functional analyses and other FBA components are most often used during research for children with autism spectrum disorder or intellectual disabilities (Anderson, Rodriguez, \& Campbell, 2015). However, there is a discrepancy between the population participating in FBA research and the population participating in FBAs during practice in schools. Conroy, Katsiyannis, Clark, Gable, and Fox (2002) reported that $60 \%$ of FBAs conducted schools are for children with emotional and behavioral challenges. Because FBAs are so commonly used for children with emotional and behavioral challenges in practice, further research on this use of the FBA technologies with children with emotional and behavioral disorders is needed.

For students with behavior challenges, school staff use indirect and descriptive assessments more often than functional analyses (Lloyd, Weaver, \& Staubitz, 2015). School staff may prefer indirect and descriptive assessments due to the substantial time required to administer functional analyses (typically longer than two hours), extraneous variables in the classroom environment (e.g., peer attention), and the complexity of functional analyses, which require professional training to implement (Anderson \& St. Peter, 2013). The time and expertise necessary may be barriers in schools, where students may be required to be out of the classroom during FBAs and individuals with sufficient expertise may not be available. Also, a functional analysis is a poor assessment choice when behavior occurs at a very low rate (e.g., peer aggression that occurs once per week) unless sessions are extended, which would only exacerbate the issue of time. 
Alternative functional-analysis methods can address the obstacles in school settings. For example, trial-based functional analyses, during which students are exposed to brief trials of test and control conditions in pairs, have been used in classrooms to identify behavioral function. Austin, Groves, Reynish, and Francis (2015) used a trial-based functional analysis while students completed independent work in their typical classrooms. The authors implemented interventions to validate functional relations identified during the trial-based functional analysis. These interventions suppressed problem behavior relative to baseline for all participants. The brief duration of each trial may allow implementers to reduce the influence of extraneous variables that could affect results during typical functional analyses in the classroom, such as peer attention (Iwata \& Dozier, 2008). However, short trials may not always be feasible if the target behavior does not occur within the brief duration of the trial.

Another alternative to traditional functional analyses is an interview-informed, synthesized contingency analysis (IISCA). An IISCA uses the results from an open-ended interview as a guide to develop an individualized pairwise functional analysis, which compares one test condition, potentially including a combination of reinforcers, with a control condition. Hanley, Jin, Vanselow, and Hanratty (2014) first interviewed the parents of three children with autism spectrum disorder who engaged in frequent problem behavior. Then, they used the interview responses to develop functional-analysis procedures for each participant. The results from the functional analysis led to the development of effective interventions for all three participants.

Most indirect assessments, including the IISCA, were designed for caregivers to complete. Interviewing caregivers may be useful or necessary for very young children or children with developmental delays, but children with complex verbal repertoires may have the 
verbal and intellectual capacity to answer questions themselves. Children's responses may be more reliable than those of a caregiver because caregivers can only report on what they observe, but the child can report about personal history or extraneous environmental variables unknown to the caregiver. Some indirect assessments have been developed for child responses. For example, Kern, Childs, Dunlap, Clark, and Falk (1994) used the Student-Assisted Functional Assessment Interview (Student-Assisted FAI) with a child with emotional and behavioral challenges. The Student-Assisted FAI uses open-ended interview items about when and where the target behavior occurs, what it looks like, and why it might occur. The experimenters developed a selfmanagement intervention based on the results from the Student-Assisted FAI, an interview with the teacher, and data collected from direct observation. The intervention and curricular modifications increased on-task behavior during spelling, reading, and math classes. Given that the intervention was based on multiple assessments and not just the Student-Assisted FAI, the extent of the contribution of the Student-Assisted FAI to the overall intervention is unknown.

Reed, Thomas, Sprague, and Horner (1997) developed an alternative to the StudentAssisted FAI called the Student-Guided Functional Assessment Interview (Student-Guided FAI). This assessment uses the same behavior-based questions as the Student-Assisted FAI, but also includes a model to build a support plan with the assistance from the person being interviewed. The experimenters compared student and teacher responses to the Student-Guided FAI. Students and teachers typically agreed on the occurrence of certain behaviors, antecedents, and consequences. Students identified more topographies of problem behavior than teachers, most likely because some topographies had not been observed by the teacher. Overall agreement on where the behavior occurred was low, which might be related to the teacher only including responses based on classroom observation. The assessment included a component for the student 
and teacher to separately develop a support plan to decrease instances of the target behavior.

Development of a support plan had low agreement, with the student focusing more on consequences and teachers focusing on antecedents. Neither the Student-Assisted FAI nor the Student-Guided FAI have received substantial further evaluation in the literature.

Informal student interviews have been included in other FBA publications. Austin et al. (2015) conducted an informal interview with their participants at the conclusion of their study about trial-based functional analyses. During the interview, experimenters asked the students which potentially function-based reward they liked the most out of all of the rewards they received during different interventions. Two of the three participants chose the reinforcers that matched the functions identified from the trial-based functional analysis. Austin et al. (2015) hypothesized that "typically developing children may be sensitive to the functions of their problem behaviors and may actually reveal those reinforcers via preference assessments" (pp. 286). Preference assessments are used to determine preferences for items or activities, and are typically used to identify preferences among snacks and toys. Austin et al. (2015) suggested further research to compare outcomes of preference assessments outcomes and functional analyses.

Preference assessments have been used with students who engage in challenging behavior to evaluate their preferences for activity-based rewards. One common preference assessment, a paired-stimulus or paired-choice preference assessment, directly compares selection between two stimuli (Fisher, Piazza, Bowman, Hagopian, Owens, \& Slevin, 1992). A multiple-stimulus-without-replacement (MSWO; DeLeon \& Iwata, 1996) preference assessment, involves presenting an array of stimuli, asking the child to select a stimulus, removing the selected stimulus from the array, and asking the child to select from the remaining stimuli. This 
process repeats until the child selects each stimulus in the array or stops selecting. The stimuli are rank-ordered based on the order of selection to identify preferred stimuli. Preference assessments, including MSWO assessments, can be modified for individuals with complex reading and verbal abilities by using written stimuli, such as presenting text on flash cards (e.g., Daly, Wells, Swanger-Gagné, Carr, Kunz, \& Taylor, 2009; King \& Kosteweicz, 2014). Daly and colleagues (2009) compared selections of written stimuli during an MSWO to activity choices after completing work. Experimenters presented an array of cards with activities written on them three times to four participants with behavior disorders. The two activity cards with the highest median rankings were considered high-preferred activities. During a reinforcer evaluation, participants selected their highest preferred activity available after work completion during $80 \%$ of opportunities. Thus, student selections during the MSWO generally matched their selections for reinforcers in the classroom.

To date, one study has directly evaluated children's preferences for events that may already maintain problem behavior (e.g. attention, escape from work or demands). Northup, George, Jones, Broussard, and Vollmer (1996) presented stimuli in a survey format, a verbal paired-stimulus preference assessment, and a pictorial paired-stimulus preference assessment. During the survey, each stimulus was presented verbally and one at a time by the experimenter and the participant was required to say whether they liked it a little, a lot, or not at all. During the verbal paired-stimulus preference assessments, two stimuli were verbally presented by the experimenter and the participant told the experimenter which stimulus they preferred most. During the pictorial paired-stimulus preference assessment, two pictures of stimuli were presented and the participant was required to pick one. The distinction between higher and lower preferred stimuli was more clear during the paired-stimulus preference assessments than when 
stimuli were presented in survey format. Northup et al. (1996) evaluated the results from the preference assessments by using a token system during which the student earned a token for completing work and the student could trade in the token for access to a stimulus. The work completion increased when children earned tokens for their highest ranked stimuli from both paired-stimulus preference assessments, relative to tokens for lowest-preferred stimuli. Although these data provide preliminary evidence that children can accurately identify stimuli that later function as reinforcers, the experimenters did not evaluate the extent to which the stimuli selected by the participants also served as reinforcers for the children's challenging behavior.

There is currently a discrepancy between the population participating in FBA research and the population receiving FBA services in schools. Options of alternative assessments are necessary for general-education students with more complex verbal repertoires, including student-informed indirect assessments. There is currently little research regarding studentreported interviews and the extent to which outcomes of preference assessments will match functional analysis outcomes is currently unknown. The purpose of the current study was to evaluate the extent to which outcomes of a student-based interview and preference assessment align with outcomes of a functional analysis for children without developmental disabilities who engage in chronic problem behavior. Additionally, we compared interventions using outcomes from the interview, preference assessment, and functional analysis to determine which assessments resulted in the development of a successful treatment package for use in the classroom.

\section{Experiment 1: Functional Behavior Assessment}

\section{Participants and Setting}


Three children who were reported by their teachers to engage in ongoing moderate to high rates of problem behavior participated in the experiment. Only students who communicated in full sentences and answered questions about their interests were enrolled in the study; the first three referred children met this criterion. We obtained consent from parents and teachers, and assent from the child participants, before beginning any study procedure.

Keith was a Caucasian 10-year-old boy diagnosed with Attention-Deficit Hyperactive Disorder, Oppositional Defiant Disorder, Obsessive-Compulsive Disorder, and Traumatic Brain Injury. Keith was in fourth grade at an alternative-education program in a classroom with a maximum of three other classmates. Keith's general-education teacher reported that Keith engaged in chronic challenging behavior across multiple settings. In the beginning of the school year, she nominated off-topic speech as the most challenging behavior because it frequently disrupted the class and preceded more intense forms of challenging behavior. Off-topic speech was defined as statements unrelated to the ongoing task or topic, excluding requests for commonly available items or accommodations. Examples of off-topic speech included swearing, talking about young children's television shows, and speech about gore or death. Nonexamples included non-word statements (e.g., "ugh") and statements relevant to the environment (e.g., "I'm cold"). Throughout the school year, Keith engaged in an increasing amount of protesting. Therefore, Keith participated twice, each time with a different target behavior. Protesting was defined as negative words (e.g., I can't, I don't want, this sucks) or non-words (e.g., grumble or moan) about a person, place, or thing. All functional assessments took place in a conference room with no people present other than the experimenter, Keith, and data collectors.

Norbert was a Caucasian 9-year-old boy in fourth grade in the same alternative generaleducation classroom as Keith. Norbert was diagnosed with Attention-Deficit Hyperactive 
Disorder. Norbert's teacher reported that Norbert interrupted and often talked out in class.

Talking out was defined as words or vocal noises at or above conversational volume without a peer or adult saying his name, pointing at him, or looking at his head or desk before a response. This definition included interrupting, which was defined as talking while an adult or peer was talking to him or to a member of his group. Saying "excuse me," a teacher's name, or asking for help when a person was not already talking was excluded from the definition. While Norbert was enrolled in the study, the alternative-education program was temporarily relocated to a local elementary school. The teacher interview, classroom observation, student-informed interview, and preference assessment took place in a classroom designated for the alternative-education program at the elementary school. The interview and preference assessments took place in the corner of the classroom over $10 \mathrm{ft}$ away from other children or adults and separated by a mobile divider. The corner of the classroom included desks and chairs for the participant, experimenter, and data collectors. The functional analysis took place at a table in the hallway at the alternativeeducation program after Norbert returned to his regular placement.

Elias was a Caucasian 11-year-old boy in fifth grade who was diagnosed with AttentionDeficit Hyperactive Disorder and Oppositional Defiant Disorder. He participated in two generaleducation classrooms and one special-education classroom at an elementary school. Each classroom included over 15 students. Elias's special-education teachers reported that Elias frequently engaged in disruptive behavior throughout his school day. Disruptive behavior was broadly defined as protesting (e.g., "I can't," "no"), yelling (voice above conversational level or the level of the classroom), threatening to harm himself or others (e.g., "I want to use this to stab myself'), hitting his head with his hand or on a surface, crying, and hissing. Elias's functional 
assessments took place in a school library with no people present other than the experimenter, Elias, and data collectors.

\section{Procedure}

Each series of assessments included a teacher interview, classroom observation, studentbased interview, preference assessment, and a functional analysis, in that order. All assessments were conducted by the same experimenter. The experimenter was an intern at the alternativeeducation program attended by Keith and Norbert, but was new to Elias's school. The experimenter terminated sessions if the student engaged in behavior warranting physical management (e.g., severe or repeated aggression) or if the student left his area and required physical guidance to return. We only had to terminate one session when Keith left his area during the off-topic speech functional analysis. Physical management was never warranted.

Data Collection. Observers were undergraduate and graduate students in a psychology program. The experimenter explained procedures and data-collection methods in detail to observers before data collection began. Observers recorded the duration of the teacher interview, classroom observation, student interview, and preference assessment by noting the start and stop times for each assessment. The computer program used for the functional analyses (described below) logged start and stop times and total durations for each session.

Observers recorded data for the student interview and preference assessment using paperpencil data. Data from the student interview were recorded on a score sheet (see Appendix A). To collect data for the student interview, observers made a check mark next to the corresponding item on the interview sheet in the frequency column corresponding to the student response, and transferred the data to a score sheet after the interview. During the preference assessment, 
observers recorded the selection made during each trial by writing a letter corresponding with the selection in the order it was selected.

During the functional analysis, observers collected data using the Behavior Logger ${ }^{\mathrm{TM}}$ data collection system (downloaded online at www.behaviorlogger.com). Observers pressed a key immediately after each instance of a target response. The program recorded the time of each keypress and output data in a summary that calculated responses per min.

Inter-observer Agreement (IOA). New data collectors were trained during sessions alongside previously trained data collectors. We considered training for an observer to be complete when that observer had interobserver agreement (IOA) scores of $90 \%$ or higher with a trained observer for three consecutive sessions, using the calculations described below. Data collectors would have been retrained if their IOA scores fell below $60 \%$ for a single session or below $80 \%$ for three consecutive sessions during the experiment, but IOA scores never fell low enough to meet requirements for retraining.

We collected IOA data for at least $33.3 \%$ of sessions for each assessment and during all student interviews. We calculated total IOA for the duration of each assessment by dividing the smaller duration by the larger duration and multiplying that number by 100 . The durations for the teacher interview, classroom observation, student interview, and functional analysis scored 100\% IOA across target behaviors. The duration for the preference assessments scored $99.3 \%$ IOA across target behaviors.

For the student interviews and preference assessments we considered identical outcomes to be agreements. We calculated IOA scores by dividing the total number of agreements by the total number of interview items or preference assessment selections for each participant. All IOA scores for the student interviews and preference assessments yielded $100 \%$ agreement. 
We calculated functional analysis IOA scores using a partial-agreement calculation. Behavior Logger ${ }^{\mathrm{TM}}$ divided the data stream into 10-s intervals and compared observers' records in each interval by dividing the smaller count by the larger count. Intervals in which neither observer scored a response yielded IOA scores of 1.0. The program then averaged the quotients across all intervals in the session and multiplied by 100 to yield a percentage. We collected IOA data for at least $33 \%$ of functional analysis sessions for each participant. The mean IOA score for Keith's off-topic behavior was $91.46 \%$ with a range from $85.2 \%$ to $100 \%$. Mean IOA score for Keith's protesting was $100 \%$. The mean IOA score for Norbert's talking out was $95.9 \%$ with a range from $87.7 \%$ to $100 \%$. The mean IOA score for Elias's disruptive behavior was $95.6 \%$ with a range from $91.3 \%$ to $100 \%$.

Treatment Integrity. The secondary observer collected treatment integrity data during each interview by circling "yes" or "no" for accuracy of pre-session instructions and each item read aloud. Treatment integrity was $100 \%$ for all interviews. During the preference assessments, the secondary observer collected treatment integrity data by assessing the accuracy of the presentation of stimuli and prompts. Treatment integrity was collected for at least $50 \%$ of trials for each participant and yielded a score of $100 \%$ for all participants.

During at least $25 \%$ of functional analysis sessions for each participant, a secondary observer collected treatment integrity by circling "yes" or "no" if appropriate materials were ready, the area was clear of extraneous materials, two-step prompts were used throughout the session when necessary, and the prescribed duration of the session was used. The experimenter's behavior was marked correct or incorrect following each student response if the experimenter followed appropriate condition contingencies following instances of the target behavior, restricted access from restricted items or removed access to restricted items within $5 \mathrm{~s}$, and 
refrained from making a statement following appropriate requests or non-target problem behavior that did not warrant physical management following each opportunity to do so. Average treatment integrity was $96.7 \%$ to $100 \%$ with a range from $92 \%$ to $100 \%$ across participants.

Teacher interview. The experimenter interviewed the classroom teacher about the participant and target behavior before beginning observations or conducting further assessments. We interviewed Keith and Norbert's general-education classroom teacher and Elias's specialeducation teachers. Before asking the interview questions, the experimenter gave the teacher a brief overview of the experiment. During this overview, the experimenter explained that the student would be taken out of class for a total of 3 to $6 \mathrm{hr}$ before the intervention began, what assessments were included in the FBA, and what the teachers would be asked to do. The experimenter then asked the interview questions reported in Appendix B and noted the teacher's responses. The experimenter used the teachers' responses to select the target behavior, to begin to develop operational definitions, and to identify questions for which the student should answer a little, sometimes, or a lot.

Classroom Observation. The experimenter observed the students to develop an operational definition of the target behavior using a narrative observation form. The experimenter made notes of all observed forms of the target behavior in detail. Details included the duration of episodes and observations as well as antecedents and consequences that tended to surround behavior. Observations continued for a minimum of three instances of the target behavior and until the experimenter developed an operational definition of the target behavior. The duration of observations are reported in Table 1. 
Student Interview. Before beginning the interview, the experimenter provided the participant with a piece of paper with "a lot, sometimes, a little" typed on it. The experimenter said the following:

I am going to ask you some questions and you can use one of three words to answer. A little can also mean never or almost never. What is something you do a little? Sometimes means every now and then. What is something you sometimes do? A lot means always or almost always. What is something you do a lot? Let's use some practice questions to begin. The participant answered each question before the experimenter continued with the script. For practice, the experimenter asked questions that the teacher suggested would produce answers of a little, sometimes, or a lot. For example, the experimenter asked Norbert how often he played with Legos ${ }^{\mathrm{TM}}$ during breaks to evoke the answer of "a lot" because the teacher reported that Norbert often played with Legos ${ }^{\mathrm{TM}}$ during breaks in class.

After practicing, the experimenter explained the target behavior using the operational definition. An example script is, "During some of these questions, I will ask about when you protest. When I say 'protest' I am talking about when you complain or say you don't want to do something." The scripts for protesting, talking out, and disruptive behavior all included a definition of the behavior. The script for off-topic speech varied because Keith said he didn't fully understand what off-topic speech was. The experimenter gave Keith a definition of the behavior and modeled the behavior using specific phrases from the classroom observations. Keith and a secondary data collector marked a tally on a sheet or paper following each instance of the modeled target behavior. After the model, the data collector and Keith reported the examples they marked a tally for. Keith and the data collector agreed about whether the modeled phrases were examples or non-examples, and Keith said he understood the definition after the 
model, so the experimenter continued with the interview. During each interview, the experimenter read one item at a time and waited up to $10 \mathrm{~s}$ for an answer. The experimenter repeated the question if the participant did not respond within $10 \mathrm{~s}$, or if the participant asked for the question to be repeated. If the participant said anything other than "a little", "sometimes", or "a lot", the experimenter instructed the participant to use one of the three response options.

Table 2 shows the items in the student interview and the function targeted by that item. We calculated the Flesch-Kincaid reading level for each item to assure the language was at or below $5^{\text {th }}$ grade reading level. During development of the interview items, five Board Certified Behavior Analysts (BCBAs) who were blind to the experimenters' categorizations sorted each item into one of three categories: escape, attention, or tangible reinforcement. Only items placed into the functional category shown in Table 2 by at least four of the BCBAs were used in the assessment. Two items were initially incorrectly sorted by two BCBAs, so we replaced those items and repeated the sorting procedure. After the second iteration, all BCBAs independently sorted all items into the intended categories.

The answers for items 1 through 21 had three possible response options (a lot, sometimes, or a little). For item 22, the experimenter removed the paper with the response options on it and told the participant to answer freely. The participant's response was transcribed verbatim. This open-ended response was not included in the identification of function. However, we report the correspondence between this item, the other items, and the other assessments for each participant in the Results section.

When the interview was over, the experimenter rated items with 2,1 , or 0 points if the participant responded, "a lot," "sometimes," or "a little," respectively. Reversed items (shown by a check in the third column of Table 2 ) received 2 points for the response "a little" and 0 points 
for the response "a lot". The totals for each condition were summed, and the condition with the highest score was used during the intervention.

Preference Assessment. We used three sets of $7 \mathrm{~cm}$ x $12 \mathrm{~cm}$ flash cards to evaluate preference for events that might reinforce problem behavior. Each set contained five cards and represented one category of event (escape, attention, tangible; see Table 3 for items). Each flash card had an event typed on it in 24-point Calibri font. The events and items on the cards were common events and items available in classrooms. We included tangible items (like a chewy pencil topper) that could be used while the students completed work and were not considered to be toys. To develop the items for the assessment, the same five BCBAs who sorted items for the student interview sorted the items from the preference assessment into categories, using an identical procedure to that used for the student interview. All items were correctly sorted into their functional categories by the five BCBAs.

Before the preference assessment, the experimenter instructed the participant to read each flash card aloud. If the participant read incorrectly, the experimenter would have read the flash card aloud and had the student repeat the card. This step was never required because each participant was able to read each card independently.

We used an MSWO arrangement to present the cards. The experimenter shuffled the cards within each set and arranged them equidistant from each other and from the participant. The experimenter told the participant to "pick the card with the option you like the most." The participant selected a card by reading the text on the card. If the student gestured at a card or did not read the card out loud, the experimenter prompted the participant to read the card out loud. After the participant selected, the experimenter removed that item from the array, rotated the remaining items from left to right, and asked the participant to make another selection. This 
process repeated until the participant selected each of the cards in the array, or until the participant refused to select after being prompted twice. These procedures were repeated for each of the three function-based stimulus sets. We then created a combined set that consisted of the first two cards chosen from each function-based set. These six flash cards were presented for a fourth MSWO. The experimenter repeated the procedures used for the other stimulus sets with this combined set.

We assigned a percentage to each selection by dividing the number of times the card was selected ( 1 for all selections) by the number of presentations of that card, and converting to a percentage. As examples, the first-selected item would receive a percentage of $100 \%$ (1 selection divided by 1 presentation); the fifth-selected card received a percentage of $20 \%$ ( 1 selection divided by 5 presentations). To calculate outcomes from the mixed set, we averaged the percentages assigned to the two items from each set. For example, if the two items from the escape set received percentages of $100 \%$ (first selection) and 33\% (third selection), the escape set would receive an overall percentage of $67 \%$. We used the function with the average highest percent selected as a potential reinforcer during the intervention.

Functional Analysis. The experimenter used a multielement design to conduct a functional analysis with three test conditions (escape, attention, and tangible) and a control condition. Each condition was signaled with a different colored discriminative stimulus (Conners, Iwata, Kahng, Hanley, Worsdell, \& Thompson, 2000). We randomized condition sequences without replacement, and conducted a minimum of three and a maximum of six sessions of each condition. Each functional-analysis session was 10-min in duration (Wallace \& Iwata, 1999). During each condition, we held consequences constant for responses other than the target behavior. 
We customized functional-analysis conditions based on information from the teacher interview and results from the preference assessments. For example, Elias's top two selections during the escape set of the preference assessment were to choose the work he gets to do and do easy work instead of hard work. During the teacher interview, Elias's teachers reported that a moderately preferred activity was basic math computation, and that he did not like social studies, reading, or writing. Therefore, during the escape condition in his functional analysis, the experimenter instructed Elias to read from a social studies text book or write a response to a question about the text. When he engaged in the target behavior, Elias could choose between math computation and using blank scrap paper however he wanted.

During each control condition, a yellow paper and preferred toys were present. The experimenter provided conversational or the participant's preferred forms of attention, as determined from the top two selections in the attention preference assessment set, at least once every $15 \mathrm{~s}$. The participant had access to their most preferred tangible items from the tangible set of the preference assessment. The experimenter refrained from giving any demands and there were no programmed consequences for the target behavior. If problem behavior was maintained by attention, access, or escape from demands, we would expect low rates of problem behavior to occur in this condition.

During each attention condition, a green paper and the top two preferred tangible items from the preference assessment were present. The experimenter acted busy reading or writing and faced away from the participant. The experimenter did not give any demands and the participant had access to tangibles, but attention was withheld unless the target behavior occurred. If the participant engaged in the target response, the experimenter provided attention for $30 \mathrm{~s}$. The type of attention provided was determined by the top two selected forms of 
attention during the preference assessment. After 30 s elapsed, the experimenter turned away and terminated attention until the next instance of target behavior.

During each escape condition, a purple (or blue, Elias only) paper, the top two preferred tangible items from the preference assessment, and work identified by the teacher were present. Students received access to tangibles and the same form of attention as what was provided in the attention condition. The experimenter followed a two-step prompt hierarchy in 10 -s intervals until the participant made a correct response. The first step was a verbal demand. If the participant did not give the correct response within $10 \mathrm{~s}$ after the verbal demand, the experimenter provided a model. If the participant did not initiate the correct response within $10 \mathrm{~s}$ after the model, the prompt hierarchy started over and repeated until the participant gave a correct response or engaged in the target response. If the participant responded correctly, the experimenter provided brief praise (e.g, "good job") and immediately presented a new demand. If the participant engaged in the target response, the experimenter stopped presenting demands for $30 \mathrm{~s}$, but left tangibles and work materials in front of the participant. After $30 \mathrm{~s}$, the experimenter presented the previous demand.

During each tangible condition, a red paper was present. For 2 min before the start of each tangible condition, the participant had access to his top two preferred items determined during the preference assessment. The highest-preferred items were available because all of the items that we included in the preference assessment were commonly available during the school day, and not considered to be toys. Therefore, we thought that these items would be unlikely to complete with attention as a reinforcer. Elias had access to his one preferred tangible item. When the session began, the experimenter removed the preferred items. Participants received conversational or their preferred forms of attention at least once every $15 \mathrm{~s}$ and the experimenter 
refrained from placing any demands. If the participant engaged in the target behavior, the experimenter gave the preferred items back and then removed the items when the 30 s elapsed. The experimenter continued to restrict access to the items until the next instance of target behavior.

Keith: Off-Topic Speech. Keith's teacher reported that structured writing was not a preferred activity, but doodling and drawing were moderately preferred. During each condition, Keith had a journal, a writing prompt (e.g., "Your favorite special at school”), a pencil, and a laminated colored piece of paper to signal which condition was in effect. Keith's preferred tangibles were a chewy pencil topper and fuzzy ball key chain. When attention was available, the experimenter provided praise for appropriate behavior (e.g., "good job using safe hands"). During the attention condition, the experimenter provided continuous conversational attention for $30 \mathrm{~s}$ following an instance of off-topic speech. During the escape condition, the experimenter followed the 2-step hierarchy by using a verbal writing prompt (e.g., "Write 'I like"”) or a model (e.g., "It's spelled I, space, 1-i-k-e. Write it"). If Keith engaged in off-topic speech, the experimenter said, "You don't have to," and turned away from Keith. During tangible and control conditions, the experimenter responded to any child-directed conversation if it was about the writing prompt.

Keith: Protesting. Later in the school year, Keith's teacher reported that grade-level math was not a preferred activity, but drawing and doodling were still moderately preferred. During each condition, Keith had a pencil with a chewy topper on it, and a laminated colored piece of paper to signal which condition was in effect. During attention, tangible, and control conditions, Keith had lined paper. Keith's available tangibles were a fidget item and fuzzy ball key chain. When attention was available, the experimenter provided praise for appropriate behavior (e.g., 
"good job using safe hands") and responded to any child-directed conversation. During the attention condition, the experimenter provided continuous conversational attention for $30 \mathrm{~s}$ following an instance of protesting. During the escape condition, the experimenter placed math worksheets in front of Keith. The experimenter followed the 2-step hierarchy by using a verbal math prompt (e.g., "Write the answer to 315 times 11") or a model (e.g., "Start by writing the answer to 5 times 1"). If Keith protested, the experimenter said, "You can do something easier," removed the math worksheet, placed the lined paper on the desk, and did not give demands for $30 \mathrm{~s}$.

Norbert: Talking Out. Norbert's teacher reported that grade-level math was not a preferred activity, but reading on a tablet was a preferred academic activity. During each condition, Norbert had a pencil and a colored math packet for which different colors signaled the condition in place. The math problems were the same during each condition; the only difference was the color of the paper. Norbert's preferred tangibles were a chewy pencil topper and an iPad. When attention was available, the experimenter provided a praise statement for appropriate behavior (e.g., staying in his seat, staying on task). During the attention condition, the experimenter provided praise statements for appropriate behavior and rule reminders to stay on task with a quiet voice. During the escape condition, the experimenter followed the two-step hierarchy by using a verbal math prompt (e.g., "Write the answer to number 1") or a model (e.g., "Start by writing the answer to 2 times 2"). If Norbert talked out, the experimenter said, "You can take a break," and turned away from Norbert.

Elias: Disruptive Behavior. Elias's teachers reported that social studies was not a preferred activity and simple math computation (e.g. multiplication, subtraction) was a preferred classroom leisure activity. During each condition, Elias had a pencil, a stack of blank paper, and 
a math worksheet printed on different colored paper to signal the condition in place. Elias's preferred tangible was a chewy pencil topper. When attention was available, the experimenter provided conversational attention and responded to any child-directed conversation. During the attention condition, the experimenter provided continuous conversational attention for $30 \mathrm{~s}$ following an instance of disruptive behavior. During the escape condition, the experimenter placed a journal with writing prompts and a social studies textbook in front of Elias. The experimenter followed the two-step hierarchy by using a verbal reading or writing prompt (e.g., "Read the first paragraph") or a model (e.g., "The sentence starts with 'In the middle.' Read the paragraph."). If Elias engaged in target behavior, the experimenter said, "You can do something easier," removed the journal and textbook, moved the math worksheets and blank paper in front of him, and did not give demands for $30 \mathrm{~s}$.

\section{Results}

Table 1 shows the duration of the teacher interview, classroom observations, student interview, preference assessment, and functional analysis for each participant. The teacher interview took an average of 15.5 minutes with a range from 12 to 18 minutes. The average duration for classroom observations was 77 minutes with a range from 16 to 186 minutes. The student interview and preference assessment took substantially less time to administer than the functional analyses. The student interview took an average of $2.9 \%$ of the time of the functional analysis across students. The preference assessment took an average of $8.4 \%$ of the time of the functional analysis.

Figure 1 shows the results for Keith's off-topic speech assessments. The top panel of Figure 1 shows results from the student interview. Keith's responses to the close-ended questions yielded a score of 11 points in the tangible category, 7 points in the attention category, and 5 
points in the escape category. These results suggested a potential tangible function for off-topic speech. When asked why he engaged in off-topic speech, Keith responded by saying, "to get a toy," which also suggested a tangible function. In this case, the suggested functions match between the open- and close-ended questions.

The middle panel in Figure 1 shows results from the mixed-set preference assessment. Appendix C shows results from each functional set. Keith's top two attention selections were to have a teacher tell him good job and to have a teacher watch him while he completed his work. Keith's top two tangible selections were to hold something soft and chew on something while he worked. Keith's top two escape selections were to do easy work instead of hard work and to get a no-homework pass. Keith selected reinforcers targeting an attention function $63 \%$ of opportunities, an escape function $42 \%$ of opportunities, and a tangible function $18 \%$ of opportunities. These results suggest a potential attention function for off-topic speech.

The bottom panel of Figure 1 shows results of the functional analysis. During the attention condition, responding occurred in the first session and was completely suppressed during the last three sessions of the condition. Responding was elevated above zero during escape, tangible, and control conditions, with a downward trend in escape and control conditions. The functional analysis was terminated before responding stabilized because the alternativeeducation program was relocated to a different school for three weeks. The temporary location did not have as much space to protect student privacy during the functional analysis, and teachers expressed concern with continuing assessments in the new location. Results from the functional analysis were inconclusive because responding during test conditions was not elevated above responding during the control condition consistently enough to make any definitive conclusions. Typically, these results would indicate an automatic-reinforcement function. However, we did 
not conduct any further assessments to test for an automatic function because off-topic speech was no longer occurring during the school day once Keith returned to the typical alternativeeducation environment.

In summary, two functions were identified for off-topic speech. The student interview identified a tangible function. The preference assessment identified an attention function. Results from the functional analysis were inconclusive. We developed an attention-based intervention and a tangible-based intervention based on the results above to reduce the rate of off-topic speech.

Figure 2 shows the results for Keith's protesting assessments. The top panel of Figure 2 shows results from the student interview. Keith's responses to the close-ended questions yielded a score of 12 points in the tangible category, 9 points in the escape category, and 6 points in the attention category. These results suggested a potential tangible function for protesting. When asked why he protested, Keith responded by saying, "so I can get a toy," which also suggests a tangible function.

The middle panel in Figure 2 shows results from the preference assessment. Appendix D shows results from each functional set. Keith's top two attention selections were to have a teacher tell him good job and read his work aloud with a teacher. Keith's top two tangible selections were to keep his hands busy during class and hold something soft while he works. Keith's top two escape selections were to get a no-homework pass and do easy work instead of hard work. However, we were unable to use the no-homework pass during the functional analysis because of the limited quantity of no-homework passes allowed by Keith's teacher. Keith selected reinforcers targeting a tangible function $63 \%$ of opportunities, an escape function 
$42 \%$ of opportunities, and an attention function $18 \%$ of opportunities. These results suggest access to items may function as a reinforcer for protesting.

The bottom panel of Figure 2 shows results of the functional analysis. Keith did not protest during any of the control or test sessions across four series of sessions (160 min). We terminated the functional analysis because the criteria stated a maximum of six series for each functional analysis. Even if Keith responded in series five or six, the data would not have been strong enough for conclusive functional analysis results. Results from the functional analysis were inconclusive. Results from the student interview and preference assessment were consistent, so we developed an intervention for a tangible function.

Figure 3 shows the results for Norbert. The top panel of Figure 3 shows results from the student interview. Norbert's responses to the close-ended questions yielded a score of 9 points in the tangible category, 8 points in the attention category, and 6 points in the escape category. The tangible category yielded the most points, suggesting a potential tangible function for talking out. When asked why he talks out, Norbert responded by saying, "to get people to pay attention to me," which suggested an attention function.

The middle panel in Figure 3 shows results from the preference assessment. Appendix E shows results from each functional set. Norbert's top two attention selections were to have a teacher watch him while he works and have a teacher tell him good job. Norbert's top two tangible selections were to chew on something while he worked and to work on a tablet instead of paper. Norbert's top two escape selections were to take a walk outside of the classroom and take a sitting break at his desk. Norbert selected reinforcers targeting a tangible function $67 \%$ of opportunities, an escape function $33 \%$ of opportunities, and an attention function $23 \%$ of 
opportunities. These results are consistent with the student interview, suggesting tangible items may function as a reinforcer for talking out.

The bottom panel of Figure 3 shows results of the functional analysis. During the control condition, an average of 0.25 responses per min (rpm; range, $0-0.50 \mathrm{rpm}$ ) occurred. Rates were similar during the attention condition, averaging $0.10 \mathrm{rpm}$ (range, $0-0.40 \mathrm{rpm}$ ). Responding was elevated during the escape $(M=2.50 \mathrm{rpm}$; range, $0.50-5.0 \mathrm{rpm})$ and tangible $(M=1.78 \mathrm{rpm}$; range, $0-4.20 \mathrm{rpm}$ ) conditions, relative to the control condition. Results from the functional analysis were consistent with results from the student interview and preference assessment, suggesting that talking out has a tangible function. Results from the functional analysis also suggested an escape function. Therefore, two interventions were developed to decrease talking out: escape and tangible.

Figure 4 shows the results for Elias. The top panel of Figure 4 shows results from the student interview. Elias's responses to the close-ended questions yielded a score of 6 points in the escape category, 5 points in the attention category, and 4 points in the tangible category. The escape category yielded the highest score, suggesting a potential escape function for disruptive behavior. When asked why he engaged in disruptive behavior, Elias responded by saying, "because I get mad and I just want to feel better," which does not suggest an escape function, and may suggest a potential automatic function.

The middle panel in Figure 4 shows results from the mixed-set preference assessment. Appendix F shows results from each functional set. Elias's only attention selection was to have the teacher tell him good job. Elias's only tangible selection was to chew on something while he worked. Elias's top two escape selections were to choose the work he gets to do and to do easy work instead of hard work. Elias selected both escape reinforcers as his top two preferred 
flashcards in the mixed set, resulting in the selection of an escape function $75 \%$ of opportunities, a tangible function $33 \%$ of opportunities, and an attention function $25 \%$ of opportunities. These results suggest escape from demands may function as a reinforcer for disruptive behavior.

The bottom panel of Figure 4 shows results of the functional analysis. During the control $(M=0.08 \mathrm{rpm}$; range, $0-0.30 \mathrm{rpm})$, attention $(M=0 \mathrm{rpm})$, and tangible $(M=0.20 \mathrm{rpm} ;$ range, 0.10-0.40 rpm) conditions, responding was suppressed to zero or near-zero rates. Rates of disruptive behavior during the escape condition were elevated above rates during all other conditions $(M=3.18 \mathrm{rpm}$; range, $1.50-5.0 \mathrm{rpm})$. Results from the functional analysis were consistent with results from the student interview and preference assessment, suggesting that escape from demands maintained Elias's disruptive behavior. Results were consistent across all functional assessments, so one intervention based on an escape function was developed and implemented.

Table 4 shows a summary of the functions identified by each assessment for each participant. The student interview and preference assessments identified identical functions for three out of four target behaviors. The function identified during the student interview and preference assessment for Elias matched the function identified during the functional analyses. The function identified during the student interview and preference assessment for Norbert matched one of the functions identified during the functional analysis. Overall, $75 \%$ of student interviews and preference assessments identified the same function and $100 \%$ of the student interviews and preference assessments matched at least one function identified in the functional analysis when it was conclusive.

\section{Discussion}


The student interview and preference assessment identified identical functions for three of four cases (all but off-topic speech for Keith). However, these outcomes only identically matched those of a functional analysis in one case (Elias). The interview and preference assessment results partially matched the functional analysis for a second case (Norbert). Norbert's functional analysis also identified a second function. Both of Keith's functional analyses were inconclusive. Overall, these results suggest that student interviews and preference assessments may not provide parallel information to that provided by a functional analysis. Nonetheless, indirect assessments like those used in this study may allow school staff to design interventions based on potential functions while more resource-intensive assessments (like functional analysis) are conducted with students.

The poor correspondence between indirect assessments and functional analyses in the current study was due, in part, to the inconclusive functional analyses obtained for two cases (both of Keith's target responses). These inconclusive results were obtained despite being conducted by highly trained staff who had considerable experience with functional analyses in schools. For off-topic speech, logistical considerations prevented a complete functional analysis. When logistical considerations prevent functional analyses, indirect assessments may provide school staff with some information upon which to create a possible function-based intervention. For protesting, no target responding occurred during any condition, despite ongoing protesting throughout Keith's school day. Keith may have been reactive to the novel environment or acted differently with the experimenter than he did with his classroom teacher. English and Anderson (2004) assessed effects of caregivers as therapists compared to novel therapists during analog functional analyses and found that different patterns of responding occurred when caregivers implemented the functional analysis. Because teachers may not always be able to implement the 
functional analysis, modified functional analyses, such as the trial-based functional analysis used by Austin and colleagues (2015), may be useful when student behavior seems reactive to new environments. Future studies could compare the student interview and preference assessment to modified functional analyses conducted in the classroom.

Although the current results suggest some promise for the use of indirect measures, the limited correspondence across assessments limits the extent to which we can predict the utility of our indirect assessments for any individual student. The student interview and preference assessment would benefit from further investigation with more participants. The assessments may not be effective for students much younger than 9 years old because a complex verbal repertoire is necessary. Additionally, Elias was the only participant in larger classrooms, and his target assessment results most clearly matched the results from the functional analysis. Replicating our findings with students in larger classrooms may show that these assessments are effective in typical general-education settings.

Austin et al. (2015) suggested the use of preference assessments to identify functions for students with complex verbal repertoires. Northup et al. (1996) found that students could identify stimuli that would function as reinforcers by using verbal stimuli in a paired-choice arrangement. The current study used written stimuli on flashcards presented in an MSWO preference assessment, which take less time to administer than paired-choice preference assessments (DeLeon \& Iwata, 1996). The shorter duration required for the preference assessment allowed substantial decreases in time out of class for the participants in this study compared to time that would have been required for paired-choice assessments like those used by Northup et al. (1996). However, MSWO assessments with written stimuli may be most useful for students who have sufficient reading skills to read each of the cards. In the current study, all students were able to 
independently read the cards, and did so after each selection. Weaker readers may not be able to discriminate between the choices presented on the cards, resulting in invalid outcomes.

During the preference assessment, the experimenter used the same verbal prompt for each target behavior. The verbal prompt was not specific to the behavior (i.e. "pick the card with the option you like the most"). This prompt addressed which events may act as reinforcers in general, not which events may already serve as reinforcers for the target behavior. Future experimenters should evaluate the role of the instruction on student selections. For example, researchers could compare a generic instruction like the one used in this study with a specific instruction, such as, “The following cards show things you may get when you protest. I'm going to ask you to pick the card with the option you'd like the most after you protest." Each following prompt can then be specific to the target behavior, such as "pick the card with the best option after you protest." It is possible that students may select differently when explicitly asked about the targeted form of challenging behavior, which may in turn reduce the likelihood of identifying a tangible function in the preference assessment.

Few studies have used student-informed indirect assessments to develop interventions in classrooms (e.g., Kern et al., 1994; Reed et al., 1997). The student interview in the current study allowed students to answer questions about their environment from a first-person perspective. Unlike previous student interviews, the close-ended questions in the current study allowed for quantitative results, potentially making results easier to interpret for individuals with limited training. However, the quantitative criteria that we used limited identification of function to a single possible reinforcer. In the review from Beavers et al. (2013), 18.9\% of the sample had multiple functions for target problem behavior, so future development of the student interview and preference assessment would benefit from including criteria for multiple functions. 
The student interview included one open-ended question asking why the student engaged in the target behavior. Keith's response matched the function identified during the close-ended questions in his student interviews for off-topic speech and protesting, but Norbert and Elias's responses did not match functions identified by the close-ended questions. Results from one question may not be strong enough to make a difference in identifying a function. Because of this, it may not be necessary to include an open-ended question during future use of the student interview. With close-ended questions alone, the student interview identified the same functions as the preference assessment for three of four target behaviors.

In the current study, the operational definition of the target behavior was informed by classroom observations. The extent to which these observations helped to guide students in their answers to the assessment is unclear. Additionally, the observations took a considerable amount of time for two target behaviors. Future researchers may consider using teacher interviews to develop operational definitions.

The indirect assessments in this study were designed for individuals with limited training to administer, but a highly trained experimenter conducted and interpreted all assessments to control for possible therapist effects across assessments. It is unlikely that staff with extensive training in functional behavior assessment will be consistently available in schools. Future research should evaluate the amount of training necessary for school professionals (e.g., school psychologists) and teachers to implement the student interview and preference assessment with high procedural fidelity.

Outcomes of functional behavior assessments are valuable only to the extent to which they result in effective, function-based intervention. Thus, when outcomes of assessments differ (as with the evaluations of off-topic speech for Keith and talking out for Norbert), comparing 
interventions based on those outcomes can help to validate the assessment. Even when intervention results align, it is useful to determine the extent to which those assessments result in effective intervention development. In Experiment 2, we used the functions identified in the student interviews, preference assessments, and functional analyses to develop interventions to suppress target behavior in the classroom.

\section{Experiment 2: Intervention}

We developed individualized interventions to reduce target challenging behavior based on the results from the assessments used in Experiment 1. The purpose was to determine the extent to which interventions based on the various assessment methods suppressed challenging behavior in the classroom context.

\section{Participants and Setting}

The same students from Experiment 1 participated in Experiment 2. The interventions for both off-topic speech and protesting for Keith took place in his general-education and specialeducation classrooms. Norbert's talking-out intervention took place in his general-education classroom at the alternative education program. Elias's disruptive behavior intervention took place in each of his three classrooms. Baseline and intervention data were collected during group instruction for all participants, during the classroom routine identified as most problematic during the teacher interview.

The experimenter implemented each intervention while class was conducted by the teacher as usual. Thus, the structure and content of lessons varied naturally over time. The same session termination criteria used in Experiment 1 was used during Experiment 2. No intervention sessions warranted physical management or termination. 


\section{Procedure}

Data Collection. The same data collection methods used during the functional analyses were used during the interventions for Keith's off-topic speech and Norbert. Specifically, observers used Behavior Logger ${ }^{\mathrm{TM}}$ to count instances of target behavior in real time. Observers sat in the back of the classroom where they could see and hear participants, but were out of participants' direct lines of sight. Observer training remained consistent with the methods used during Experiment 1.

For Keith's protesting intervention, we initially collected data during short observations with the Behavior Logger ${ }^{\mathrm{TM}}$ program. However, response rates were very low and did not reflect the higher, variable rates captured in data collected by classroom staff throughout the day. Thus, we suspected that Keith may have been reactive to the presence of extra data collectors with computers in the classroom. To address this potential reactivity, we implemented day-long sessions and used the paper-pencil data collection system typically used by Keith's teacher. The data collector marked a tally following each instance of protesting in 30-min intervals throughout Keith's school day.

Data collection procedures were different for Elias's intervention because few data collectors could travel to Elias's school, and sessions were not video-recorded because video consent was not granted from other students in Elias's classrooms. The primary data collector used Behavior Logger ${ }^{\mathrm{TM}}$ to collect computerized data. The experimenter served as the secondary data collector, and used a finger counter to count each instance of disruptive behavior.

Interobserver Agreement (IOA). We calculated IOA scores for Keith's off-topic and Norbert's talking-out interventions using Behavior Logger ${ }^{\mathrm{TM}}$. We used the same partialagreement IOA calculations described in Experiment 1. We used a partial-agreement method for 
Keith's protesting IOA by comparing observer data in 30-min blocks. We calculated total IOA for Elias's disruptive behavior intervention by dividing the smaller count by the larger count and multiplying by 100 for each session. We collected IOA data for 35\% of sessions for Keith's offtopic intervention, with a mean score of $94.7 \%$ and range from $80.6 \%$ to $100 \%$. We collected IOA data for $56.2 \%$ of 30-min blocks across school days for Keith's protesting intervention, with a mean score of $95.6 \%$ and range from $92.3 \%$ to $100 \%$. We collected IOA data for $47.6 \%$ of sessions for Norbert's talking-out intervention, with a mean score of $96.7 \%$ and range from $85.2 \%$ to $100 \%$. We collected IOA data for $73.3 \%$ of sessions for Elias's disruptive behavior, with a mean score of $95.5 \%$ and range from $75 \%$ to $100 \%$.

Treatment Integrity. A secondary observer used a checklist to collect treatment integrity on the experimenter during at least $25 \%$ of intervention sessions for each participant. Average treatment integrity scores ranged from $97.7 \%$ to $100 \%$ across participants, with a mean of $99.2 \%$ and individual session integrity never falling below $85 \%$ for any of the interventions.

We used a checklist to collect treatment integrity data on teacher and staff demands and monitored adult attention using Behavior Logger ${ }^{\mathrm{TM}}$ during Norbert and Elias's interventions. During escape-based intervention sessions, teachers and classroom staff were instructed not to give demands during escape periods. Teachers and staff refrained from giving demands during all escape periods throughout Norbert and Elias's escape-based interventions. We monitored adult attention to make sure adult attention following the target behavior did not vary across conditions. We considered attention to be a consequence for the target behavior if it occurred within $3 \mathrm{~s}$ following the target behavior. During Norbert's no-intervention condition, teachers and staff refrained from providing attention following $91.8 \%$ of instances of talking out across sessions. During Norbert's three intervention conditions, teachers and staff refrained from 
providing attention following an average of $96.6 \%$ of instances of talking out, with a range from $92.4 \%$ to $100 \%$ across interventions. During Elias's no-intervention and intervention conditions, teachers and staff refrained from providing attention following $100 \%$ of instances of disruptive behavior.

Baseline. We started each evaluation with a baseline phase to establish rates of challenging behavior with previously existing behavior-management procedures used by the teacher. During baseline sessions, the experimenter sat with a laptop approximately $10 \mathrm{ft}$ away from the participant. If the participant asked for the experimenter's attention, the experimenter told him she was unavailable. The experimenter ignored any additional requests in the session.

Intervention. During the intervention phase, we used a multi element design to compare intervention conditions with a no-intervention condition based on each potential function identified in previous assessments. The no-intervention condition differed from baseline only in that we instructed participants before each no-intervention sessions; baseline sessions did not include an instruction. Specific instructions delivered to each participant are described below. Before the start of intervention sessions, the experimenter informed the classroom teachers of the details of the intervention and usually told the teachers to interact with the student as they normally would (excluding escape-based interventions for which teachers and staff were told not to place any demands on the participant). For Keith and Elias, intervention consisted of access to the potential reinforcer identified in a previous assessment independently of responding (noncontingent reinforcement). For Norbert, intervention consisted of access to the potential reinforcer following an appropriate response (differential reinforcement of alternative behavior; DRA). The details of interventions were selected based on fit with the classroom context, and are described in more detail below. 
Keith: Off-Topic Speech. We began baseline data collection for the interventions 20 days after the conclusion of the FA, once Keith returned to the alternative-education program from the temporary relocation. Because Keith's teacher originally reported that off-topic speech occurred during all academic activities, we collected baseline data during independent, structured activities and group-academic instruction during which Keith was seated at his desk or at a table with the teacher and peers. Sessions were $10 \mathrm{~min}$ in duration. We would have implemented an intervention based on a tangible function and an intervention based on an attention function, but the target behavior occurred at such low rates during baseline that intervention was not necessary.

Keith: Protesting. Low rates of responding emerged during 10-min sessions of baseline, similar to the pattern during Keith's off-topic speech baseline. Keith only protested during one of the last five sessions of baseline. Because teachers continued to report that protesting was a concern, we began day-long intervention sessions using classroom daily behavior data as a baseline. The session duration was the school day, starting when Keith arrived at school and ending when he left. We used noncontingent access to tangibles without extinction for two reasons. First, the experimenter could not be at the school all day but could arrive each morning to provide instructions and, during intervention days, access to the items. Second, teachers could respond as they normally would without compromising the integrity of the intervention. We felt that using noncontingent access might reduce possible lapses in treatment integrity during the intervention.

The experimenter explained the procedures of each condition when Keith arrived at school. During the no-intervention condition, the procedures were the same as they were during baseline except that the experimenter told Keith, "The fidget and fuzzy ball are not available 
today." At the start of an intervention day, the experimenter gave Keith his preferred items and told him, "The fidget and fuzzy ball are available all day today." The classroom staff were told to respond to target and non-target behavior according to his daily behavior plan. Keith's behavior plan stated that teachers and staff should not comment or respond to protests (e.g., arguing). During the first day of the intervention, Keith broke the fidget toy within the first two hours of the day. Keith did not have access to a fidget toy for the remainder of the first session or the second intervention session. For the rest of the intervention sessions, we replaced the fidget toy used in the functional analysis and first intervention session with a rubber fidget ring that could not be broken.

Norbert: Talking Out. During no-intervention sessions, Norbert had a $7 \mathrm{~cm} \mathrm{x} 12 \mathrm{~cm}$ white card with the word "other" typed on it. The experimenter told Norbert, "If you need anything, raise the white card over your head quietly, without talking. Just remember to raise your hand with the card if you want to talk." The white card was also available during each intervention session.

We used DRA as the intervention for Norbert's talking out. We targeted hand-raising as the alternative behavior. During the teacher interview, Norbert's teacher reported that he did not raise his hand and called out instead. Hand-raising was a socially acceptable replacement behavior, and DRA allowed us to try to strengthen that behavior. Based on the functional assessment results, we developed two DRA interventions: tangible and escape. During both interventions, the therapist sat approximately $3 \mathrm{~m}$ behind Norbert. Talking out resulted in no programmed consequences from the experimenter, and raising a $7 \mathrm{~cm} \times 12 \mathrm{~cm}$ colored card was followed by the prescribed consequence after each instance on a fixed ratio (FR) 1 schedule. We used a card to allow Norbert to make an appropriate request during class and to let the 
experimenter know what he was requesting without talking out. Before each intervention session, the experimenter told the classroom staff which intervention would be implemented. During intervention sessions, the experimenter placed two FCR cards on Norbert's desk: the white card and a colored card with the name of the reinforcer ("chewy \& tablet" or "break") typed on it in 24-point Calibri font. The experimenter said,

If you quietly raise your hand without talking while holding the [blue] card, [I will give you your chewy and tablet]. If you want more time, you just need to quietly raise the card above your head again. If you need anything else, quietly raise the white card over your head. Just remember to raise your hand without talking.

There was a 3-s changeover delay in place; if Norbert raised a card and talked out at the same time, the experimenter did not give the prescribed consequence until there was $3 \mathrm{~s}$ between talking out and card raising.

Two contingencies were identical across all conditions. If Norbert quietly raised the white FCR card above his head, the therapist stayed seated behind him and asked, "Yes?" During this time, the experimenter responded to questions. If Norbert engaged in any target or non-target challenging behavior, the experimenter did not respond. Teachers and classroom staff were instructed to respond to the target behavior as they normally would. Data on teacher and staff responses during each intervention are reported with the results.

The tangible intervention was associated with a blue FCR card with the words "chewy \& tablet" typed on it. If Norbert quietly raised the blue FCR card above his head, the experimenter placed the tablet, a stylus pen, and the chewy on his desk. The teacher still provided demands and Norbert was expected to complete his work as usual. After $30 \mathrm{~s}$ elapsed, the experimenter stood next to Norbert and said, "If you want more time with these, raise the blue card silently" 
and immediately began removing the items. If Norbert raised the blue FCR card without talking out, the therapist placed the items back on the desk and stepped away for 30s.

The escape intervention was associated with a yellow FCR card with the word "break" typed on it. If Norbert quietly raised the yellow FCR card above his head, the experimenter put a sign saying, "I am on a break" on the front of Norbert's desk and stepped away. Before starting each escape session, the experimenter told the teacher not to place any demands on Norbert while the break sign was on his desk. After 30 s elapsed, the experimenter stood next to Norbert and said, "Raise the yellow card quietly if you want more time on break. If not, [presents ongoing classroom demand]" and immediately removed the break sign. If Norbert raised the yellow FCR card without talking out, the experimenter placed the break sign back on Norbert's desk.

The final phase of the intervention included an escape-to-tangibles condition. We thought that the first two interventions may have been ineffective because Norbert did not have anything to access on his break and he did not get a break from work when he had tangible items. The synthesized intervention was associated with a half-yellow and half-blue card with the words "break \& items" typed on it. If Norbert quietly raised the card above his head, the experimenter put the break sign, tablet, stylus pen, and chewy on Norbert's desk and stepped away for $30 \mathrm{~s}$. During this interval, no demands or questions were presented and Norbert had access to all items on his desk. After 30 s elapsed, the experimenter stood next to Norbert and said, "Raise the yellow and blue card quietly if you want more time on break with the items. If not, [presents ongoing classroom demand]" and immediately started removing the items and sign. If Norbert raised the yellow and blue FCR card without talking out, the therapist placed the items and break sign back on the desk and stepped away. 
Elias: Disruptive Behavior. Responding occurred once during the last 10 sessions of baseline. We suspected Elias may have been reactive to the presence of the experimenter, observers collected data while the experimenter was out of the room for the last two sessions of baseline. Disruptive behavior did not occur during the last two sessions. Teachers also reported that Elias had not been engaging in disruptive behavior as frequently during the previous few weeks. Therefore, we initially thought intervention was not warranted. However, the teachers reported an increase in disruptive behavior to us 4 weeks after the last baseline session. We began the intervention phase after this communication, without conducting an additional baseline phase.

During the no-intervention condition, the procedures were the same as they were during the previous baseline except that the experimenter started every session by telling Elias, "You need to work on what the class is doing."

Intervention sessions consisted of activity choice with the option of escape from the ongoing task in the classroom. We used noncontingent escape to chosen work because it only required the experimenter to interact with Elias one time per session. The intervention did not interrupt classroom instruction and would have been possible for a teacher or classroom aide to implement in the absence of the experimenter. The therapist provided three task options to Elias before the start of each intervention session: the classroom task and two tasks (ReadingLanguage Arts, or RLA, and a math worksheet) that the teachers reported Elias liked to do. The therapist told Elias, "You can keep working on this [classroom task], or you may read your RLA book or do this math. You can work on any of these tasks. It's your choice.” The session started immediately after the experimenter gave Elias the three tasks. During the session, teachers could offer to help Elias or respond to any questions he had, but did not present demands. The teachers 
followed this rule during each intervention session. The therapist sat approximately $10 \mathrm{ft}$ away from Elias while acting busy. The experimenter responded to any requests from Elias in the same way she did during baseline and no-intervention sessions.

\section{Results}

Keith: Off-Topic Speech. The top panel of Figure 5 shows results from Keith's off-topic baseline. We conducted 20 baseline sessions and the mean response rate was 0.25 statements per min, with a range between 0 and 1.10 statements per min. Response rates during the last five sessions of baseline ranged between 0 and 0.10 statements per min. After 20 sessions of low response rates during baseline, the experimenter asked the teacher if there was a different time during the day that off-topic speech occurred. The teacher reported that off-topic speech had stopped occurring frequently and was no longer a concern. The interventions were no longer needed and therefore were not implemented.

Keith: Protesting. The second panel of Figure 5 shows results from Keith's protesting intervention. The pattern of protesting during baseline was similar to that seen during baseline of Keith's off-topic speech. Protesting occurred at low rates during the first several sessions of baseline, increased for five sessions, and then decreased to zero or near zero rates. Yet, Keith's teacher reported that protesting continued to occur at variable, elevated rates throughout the school day. When we incorporated day-long sessions (sessions 21 through 31), protesting occurred more consistently. Protesting occurred an average of 9.75 responses per hour (rph) during no-intervention sessions (range, 4.77-20.46 rph). During intervention sessions, protesting occurred an average of $3.58 \mathrm{rph}$ (range,1-7.23 rph). Response rates during each intervention session consistently remained below rates during no-intervention sessions during the last 10 out of 11 sessions. 
Norbert: Talking Out. The third panel of Figure 5 shows results for Norbert. Responding during the baseline phase stabilized during the last three sessions, with an average of 1.70 responses per min. The second phase included a multielement design with two interventions and a no-intervention condition. During the escape intervention, responses ranged between 0.80 and $2.50 \mathrm{rpm}(M=1.64 \mathrm{rpm})$. During the tangible intervention, responses ranged between 0.40 and $1.20 \mathrm{rpm}(M=0.76 \mathrm{rpm})$. Responding during the no-intervention condition ranged between 0.70 and 1.40 responses per $\min (M=1.17 \mathrm{rpm})$. Although mean rates were lower in the tangible condition than the no-intervention condition, the considerable overlap between the data paths suggests no reliable suppressive effects of the tangible intervention. The final phase included a no-intervention condition and an escape-to-tangible synthesized intervention, as described in the Method section. Responding ranged between 0.40 and $2.20 \mathrm{rpm}(M=1.16 \mathrm{rpm})$ during the escape-to-tangible intervention condition and between 1.30 and $2.80 \mathrm{rpm}(M=1.91 \mathrm{rpm})$ during the no-intervention condition. Although it seemed that differentiation in responding across conditions may have been emerging, we were unable to continue data collection because Norbert transitioned out of the alternative-education environment.

Elias: Disruptive Behavior. The bottom panel of Figure 5 shows results for Elias. Disruptive behavior did not occur during 9 out of the last 10 sessions of baseline. Because of these low rates, we terminated sessions. We resumed sessions in the intervention phase 4 weeks later, when teachers reported that disruptive behavior was consistently occurring. During the intervention phase, responding occurred an average of 0.20 instances per min during nointervention sessions (range, 0-0.50 rpm). During intervention sessions, responding occurred an average of 0.03 instances per min (range, 0-0.20 rpm). Responding during intervention sessions consistently occurred less frequently than during no-intervention sessions. 


\section{Discussion}

We addressed the second aim of the current study by developing interventions based on outcomes from the student interview, preference assessment, and functional analysis. We were unable to validate the assessments for off-topic speech because of overall low response rates. We effectively suppressed responding for two of the other three cases with interventions based on assessment outcomes. For both cases (protesting for Keith and disruptive behavior for Elias), results from the assessments aligned. For the third case (talking out for Norbert), assessment results did not align, and neither intervention suppressed behavior compared to no-intervention sessions.

At least two variables may have contributed to the ineffective interventions for Norbert. First, it is possible that none of the assessments captured the function of Norbert's behavior in the classroom, or that the function of the behavior shifted across time. For example, descriptive analyses may have been used to identify idiosyncratic reinforcers. Second, Norbert was the only student for whom we used differential reinforcement instead of noncontingent reinforcement. The noncontingent interventions required little interaction between the experimenter and the student in the classroom, but the DRA interventions were very intrusive. During each DRA intervention, the experimenter reminded Norbert to raise the card before the start of the session and following each reinforcer period. In doing so, she frequently interrupted Norbert's classroom instruction. Although DRA has been an effective intervention for a variety of behavior (e.g., Carr \& Durand, 1985; St. Peter Pipkin, Vollmer, \& Sloman, 2010; Piazza, Moes, \& Fisher, 1996), it is often preceded by a DRA training phase in which more intrusive procedures are initially used and reduced over time. For Norbert, we continued to use prompting throughout the evaluation. 
Using more typical DRA procedures, or noncontingent-reinforcement procedures like those used for Keith and Elias, may have effectively suppressed talking out.

Three of four target responses occurred at low rates during initial baseline data collection. Off-topic speech reportedly decreased throughout Keith's school day after his return from the temporary placement, which explains why we were unable to capture frequent responding during baseline. However, protesting occurred at high, variable rates throughout Keith's school day but did not occur during nine out of the last ten 10-min baseline sessions. Keith may have been responsive to data collectors with computers in the room or, because of the reported variability in protesting throughout the day, data collectors may not have captured the behavior in 10-min observations. Full-day sessions resolved the issue of low rates of protesting. Elias responded at low rates during baseline, and again during all sessions after the 20-day period since baseline, despite teacher reports of an increase in disruptive behavior. At the conclusion of the study, teachers reported that Elias acted more appropriately when data collectors were present, suggesting that Elias may have been reactive to unfamiliar data collectors with computers in the classroom. Despite the limitation of low-rate behavior during 10-min sessions, interventions based on assessment results still effectively suppressed responding for both Keith and Elias.

During each intervention, the experimenter acted as the main therapist. Teacher behavior was not manipulated unless an escape intervention was in place, during which the teacher was told not to present demands when the student was in an escape period. We did not monitor teacher behavior during Keith's protesting intervention, so it is unknown whether teachers and staff responded differently to protesting during intervention and no-intervention sessions. The only difference between days with and without the intervention was the staff telling the teacher if the intervention was in place, the initial instruction in the beginning of the day, and the presence 
of the fidget and fuzzy ball, which seems unlikely to strongly influence teacher behavior. However, future researchers may wish to more carefully control for possible extraneous variables like teacher-student interactions.

\section{General Discussion}

During Experiment 1, we evaluated the extent to which outcomes of a student-based interview and preference assessment aligned with functional analysis results from students with complex verbal repertoires. Assessment results aligned for Elias's disruptive behavior.

Functional analysis results were inconclusive for Keith's off-topic speech and protesting, so we were unable to assess whether results aligned. The functional analysis identified two functions for Norbert's talking out; one function aligned with the student interview and preference assessment outcomes and the other did not. During Experiment 2, we used the results of the FBA in Experiment 1 to implement interventions in the students' classrooms, and compared response rates during the intervention to rates when the intervention was not in place. Interventions based on the student interview and preference assessment effectively suppressed target responding compared to no-intervention sessions for two of three students. These results suggest that indirect student assessments, like the interviews and preference assessments in the current study, may identify reinforcers that can be effectively used in behavior intervention plans for students with complex verbal repertoires.

The student interview and preference assessment address some of the problems that make functional analyses difficult to conduct with general-education students. Functional analyses can take considerable time to complete, which may restrict their use with general-education students. In the current study, the student interview and preference assessment took substantially less time to administer than a functional analysis. Additionally, functional analyses are intended to evoke 
challenging behavior, so removal from the classroom may be necessary. The student interview and preference assessment were not designed to evoke challenging behavior, so teachers may find them more acceptable than functional analyses for classroom use. Alternative functional analyses, such as trial-based functional analyses, may also limit assessment duration and the extent to which challenging behavior is repeatedly evoked and reinforced. Future research should compare the social validity of typical functional analysis procedures, trial-based functional analyses, and indirect measures for teachers and other classroom staff.

High social validity must be tempered by the utility of the assessment. Although standard functional-analysis procedures are supported through thousands of replications (e.g., Beavers et al., 2013), most of those studies were conducted with individuals with intellectual or developmental disabilities, not with highly verbal students in general education classrooms (Anderson \& St. Peter, 2013). Alternative function-analysis procedures, like trial-based functional analysis, have received some support for classroom use (e.g., Austin et al., 2015). However, trial-based functional analyses may not capture low-rate behavior in the classroom if a response does not occur within the short duration of the trial. Despite initial teacher reports that each target response occurred frequently, low rates of responding occurred during baseline for three target responses in the current study. These low rates may have resulted in false negative outcomes in trial-based analyses, like the potential false-negative results obtained for the functional analysis of Keith's protesting. The student interview and preference assessment allowed us to develop interventions that suppressed responding despite these already-low baseline rates. Along with effective results, an evaluation of social validity could have shown us whether the indirect assessments were acceptable in the classroom. Future researchers should 
include a social validity component to test whether the teachers found the indirect assessments to be acceptable in the student's school day and in the classroom.

Responding during Keith's functional analyses and Keith and Elias's interventions may have been influenced by the novel experimenter. Students occasionally respond differently when new therapists implement assessments or interventions (English \& Anderson, 2004). The procedures used in this study should be replicated with the teacher as the implementer during the functional analysis and intervention. Using the teacher as the implementer may result in higher rates of target responding, like the rates reported during the teacher interview. During this replication, researchers could also assess differences in time required to train teachers to implement the indirect assessments and the functional analysis.

Most existing indirect assessments (e.g., Functional Analysis Screening Tool, Motivation Assessment Scale, Questions About Behavioral Function Scale) are administered to caregivers rather than the child engaging in the behavior. Future research should assess the correspondence between caregiver and student reports. In the current study, we interviewed the teacher, but the structure of the interviews between teacher and student varied too much to permit direct comparison of outcomes. If outcomes do not align between caregiver and student reports, interventions based on the functions identified by students and caregivers could be compared to determine the most effective interview method.

Previous reviews of indirect assessments report inconsistent reliability and validity, with reports of moderate to good outcomes (e.g., Smith, Smith, Dracobly, \& Peterson Pace, 2012; McIntosh, Borgmeier, Anderson, Horner, Rodriguez, \& Tobin, 2008) and reports of poor or limited outcomes (e.g., Sturmey, 1994; Iwata et al., 2013). Results from the student interview and preference assessment fully or partially aligned with conclusive functional analysis results 
for Elias and Norbert. However, we were unable to fully assess reliability due to inconclusive results for both of Keith's functional analyses. We developed function-based interventions to validate the assessments. Two of three interventions effectively suppressed target responding. Reliability and validity of the student interview and preference assessment are consistent with the moderate to good reviews of previous indirect assessments, but better alignment between assessments is still preferred. Further development of the assessments can improve reliability and validity scores. For example, additional idiosyncratic items from teacher reports can be included in either the student interview or preference assessment. Further reviews of reliability and validity of the student interview and preference assessment are also warranted to assess for whom the assessments are most reliable and valid.

The current study shows that the student interview and preference assessment can be used to develop effective function-based interventions. More research is warranted to support these results, including research with a population of different ages and in larger classrooms. These assessments took substantially less time to administer than a functional analysis and would be relatively simple to add to any future FBA research because of this limited time requirement. Student-reported indirect assessments decrease time required by third parties (e.g., parents, teachers) and the current assessments require much less time out of the classroom for the student than functional analyses. Student-reported assessments may be more feasible for the generaleducation population without disabilities, and the student interview and preference assessment can lead research in a direction for development of assessments targeting this population. 


\section{References}

Anderson, C. M., Rodriguez, B. J., \& Campbell, A. (2015). Functional behavior assessment in schools: Current status and future directions. Journal of Behavioral Education, 24(3) 338-371. doi: 10.1007/s10864-015-9226-Z

Anderson, C. M., \& St. Peter, C. C. (2013). Functional analysis with typically developing children: Best practice or too early to tell?: In response to Hanley (2012). Behavior Analysis in Practice, 6(2), 62-76. doi: 10.1007/BF03391806

Austin, J. L., Groves, E. A., Reynish, L. C., \& Francis, L. L. (2015). Validating trial-based functional analyses in mainstream primary school classrooms. Journal of Applied Behavior Analysis, 48(2), 274-288. doi: 10.1002/jaba.208

Beavers, G. A., Iwata, B. A., \& Lerman, D. C. (2013). Thirty years of research on the functional analysis of problem behavior. Journal of Applied Behavior Analysis, 46(1), 1-21. doi: 10.1002/jaba.30

Carr, E. G., \& Durand, V. M. (1985). Reducing behavior problems through functional communication training. Journal of Applied Behavior Analysis, 18(1), 111-126. doi: 10.1901/jaba.1985.18-111

Connors, J., Iwata, B. A., Kahng, S., Hanley, G. P., Worsdell, A. S., \& Thompson, R. H. (2000) Differential responding in the presence and absence of discriminative stimuli during multielement functional analyses. Journal of Applied Behavior Analysis, 33(3), 299-308. doi: 10.1901/jaba.2000.33-299 
Conroy, M. A., Katsiyannis, A., Clark, D., Gable, R. A., \& Fox, J. J. (2002). State office of education practices implementing the IDEA disciplinary provisions. Council for Exceptional Children, 27(2), 98-108. doi: 10.1177/019874290202700201

Daly, E. J., Wells, N. J., Swanger-Gagné, M.S., Carr, J. E., Kunz, G. M., \& Taylor, A. M. (2009). Evaluation of the multiple-stimulus without replacement preference assessment method using activities as stimuli. Journal of Applied Behavior Analysis, 42(3), 563-574. doi: 10.1901/jaba.2009.42-563

DeLeon, I. G., \& Iwata, B. A. (1996). Evaluation of a multiple-stimulus presentation format for assessing reinforcer preferences. Journal of Applied Behavior Analysis, 29(4), 519-533. doi: 10.1901/jaba.1996.29-519

Drasgow, E., \& Yell, M. L. (2001). Functional behavioral assessments: Legal requirements and challenges. School Psychology Review, 30(2), 239-251.

English, C. L., \& Anderson, C. M. (2004). Effects of familiar versus unfamiliar therapists on responding in the analog functional analysis. Research in Developmental Disabilities, 25, 39-55. doi: 10.1016/j.ridd.2003.04.002

Fisher, W., Piazza, C. C., Bowman, L. G., Hagopian, L. P., Owens, J. C., \& Slevin, I. (1992). A comparison of two approaches for identifying reinforcers for persons with severe and profound disabilities. Journal of Applied Behavior Analysis, 25(2), 491-498. doi: 10.1901/jaba.1992.25-491

Hanley, G. P. (2012). Functional assessment of problem behavior: Dispelling myths, overcoming implementation obstacles, and developing new lore. Behavior Analysis in Practice, 5(1), 54-72. doi: 10.1007/BF03391818 
Hanley, G. P., Iwata, B. A., \& McCord, B. E. (2003). Functional analysis of problem behavior: A review. Journal of Applied Behavior Analysis, 36(2), 147-185. doi:

10.1901/jaba.2003.36-147

Hanley, G. P., Jin, C. S., Vanselow, N. R. and Hanratty, L. A. (2014). Producing meaningful improvements in problem behavior of children with autism via synthesized analyses and treatments. Journal of Applied Behavior Analysis, 47(1), 16-36. doi: 10.1002/jaba.106

Iwata, B. A., DeLeon, I. G., Roscoe, E. M. (2013). Reliability and validity of the functional analysis screening tool. Journal of Applied Behavior Analysis, 46(1), 271-284. doi: 10.1002/jaba.31

Iwata, B. A., Dorsey, M. F., Slifer, K. J., Bauman, K. E., \& Richman, G. S. (1994). Toward a functional analysis of self-injury. Journal of Applied Behavior Analysis, 27(2), 197-209. (Reprinted from Analysis and Intervention in Developmental Disabilities, 2, 3-20, 1982). doi: 10.1901/jaba.1994.27-197

Iwata, B. A., \& Dozier, C. L. (2008). Clinical application of functional analysis methodology. Behavior Analysis in Practice, 1(1), 3-9. doi: 10.1007/BF03391714

Iwata, B. A., Kahng, S., Wallace, M. D., \& Lindberg, J. S. (2000). The functional analysis model of behavioral assessment. In Austin, J., \& Carr, J. (Eds.), Handbook of applied behavior analysis (61-89). Oakland, CA: New Harbinger Publications.

Iwata, B. A., Pace, G. M., Kalsher, M. J., Cowdery, G. E., \& Cataldo, M. F. (1990). Experimental analysis and extinction of self-injurious escape behavior. Journal of Applied Behavior Analysis, 23(1), 11-27. doi: 10.1901/jaba.1990.23-11 
Kern, L., Childs, K. E., Dunlap, G., Clarke, S., Falk, G. D. (1994). Using assessment-based curricular intervention to improve the classroom behavior of a student with emotional and behavioral challenges. Journal of Applied Behavior Analysis, 27(1), 7-19. doi: 10.1901/jaba.1994.27-7

Lalli, J. S., Browder, D. M., Mace, F. C., \& Brown, D. K. (1993). Teacher use of descriptive analysis data to implement interventions to decrease students' problem behaviors. Journal of Applied Behavior Analysis, 26 (2), 227-238. doi: 10.1901/jaba.1993.26-227

Lloyd, B. P., Weaver, E. S., \& Staubitz, J. L. (2015). A review of functional analysis methods conducted in public school classroom settings. Journal of Behavioral Education, 1-33. doi: 10.1007/s10864-015-9243-y

McIntosh, K., Borgmeier, C., Anderson, C. M., Horner, R. H., Rodriguez, B. J., \& Tobin, T. J. (2008). Technical adequacy of the functional assessment checklist: Teachers and staff (FACTS) FBA interview measure. Journal of Positive Behavior Interventions, 10(1), 3345. doi: $10.1177 / 1098300707311619$

Meyer, K. A. (1999). Functional analysis and treatment of problem behavior exhibited by elementary school children. Journal of Applied Behavior Analysis, 32(2), 229-232. doi: 10.1901/jaba.1999.32-229

Northup, J., George, T., Jones, K., Broussard, C., Vollmer, T. R. (1996). A comparison of reinforcer assessment methods: The utility of verbal and pictorial choice procedures. Journal of Applied Behavior Analysis, 29(2), 201-212. doi: 10.1901/jaba.1996.29-201

Paclawskyj, T. R., Matson, J. L., Rush, K. S., Smalls, Y., Vollmer, T. R. (2000). Questions about behavioral function (QABF): A behavioral checklist for functional assessment of aberrant 
behavior. Research in Developmental Disabilities, 21, 223-229. doi: 10.1016/S08914222(00)00036-6

Piazza, C. C., Moes, D. R., \& Fisher, W. W. (1996). Differential reinforcement of alternative behavior and demand fading in the treatment of escape-maintained destructive behavior. Journal of Applied Behavior Analysis, 29(4), 569-572. doi: 10.1901/jaba.1996.29-569

Reed, H., Thomas, E., Sprague, J. R., \& Horner, R. H. (1997). The student guided functional assessment interview: An analysis student and teacher agreement. Journal of Behavioral Education, 7(1), 33-49. doi: 10.1023/A:1022837319739

Smith, C. M., Smith, R. G., Dracobly, J. D., \& Peterson Pace, A. (2012). Multiple-respondent anecdotal assessments: An analysis of interrater agreement and correspondence with analogue assessment outcomes. Journal of Applied Behavior Analysis, 45(4), 779-795. doi: 10.1901/jaba.2012.45-779

St. Peter Pipkin, C., Vollmer, T. R., \& Sloman, K. N. (2010). Effects of treatment integrity failures during differential reinforcement of alternative behavior: A translational model. Journal of Applied Behavior Analysis, 43, 47-70. doi: 10.1901/jaba.2010.43-47

Sturmey, P. (1994). Assessing the functions of aberrant behaviors: A review of psychometric instruments. Journal of Autism and Developmental Disorders, 24(3), 293-304.

Vollmer, T. R., \& Iwata, B. A. (1992). Differential reinforcement as treatment for behavior disorders: Procedural and functional variations. Research in Developmental Disabilities, 13, 393-417. doi: 10.1016/0891-4222(92)90013-V 
Vollmer, T. R., Borrero, J. C., Wright, C. S., Van Camp, C., \& Lalli, J. S. (2001). Identifying possible contingencies during descriptive analyses of severe behavior disorders. Journal of Applied Behavior Analysis, 34(3), 269-287. doi: 10.1901/jaba.2001.34-269 
Table 1.

Assessment Durations (min)

\begin{tabular}{lcccc}
\hline Assessment & $\begin{array}{c}\text { Keith Off- } \\
\text { Topic Speech }\end{array}$ & Keith Protest & $\begin{array}{c}\text { Norbert } \\
\text { Talking Out }\end{array}$ & $\begin{array}{c}\text { Elias } \\
\text { Disruption }\end{array}$ \\
\hline Teacher Interview & 18 & 14 & 12 & 18 \\
Classroom Observation & 89 & 17 & 16 & 186 \\
Student Interview & 5 & 3 & 3 & 7 \\
Preference Assessment & 14 & 11 & 11 & 16 \\
Functional Analysis & 180 & 120 & 170 & 160
\end{tabular}


Table 2.

Student Interview Items and Functions

\begin{tabular}{|c|c|c|c|}
\hline Item \# & Item & Function & Reverse \\
\hline 1 & Is your work too hard for you? & Escape & \\
\hline 2 & $\begin{array}{l}\text { Do you like it when a teacher notices you when you are } \\
\text { [target behavior]? }\end{array}$ & Attention & \\
\hline 3 & Do you [target behavior] so you can get access to a toy? & Tangible & \\
\hline 4 & Do you feel okay when you're left alone while working? & Attention & $\checkmark$ \\
\hline 5 & $\begin{array}{l}\text { Do you [target behavior] when a person takes something } \\
\text { away from you? }\end{array}$ & Tangible & \\
\hline 6 & Is it easier to [target behavior] than do your work? & Escape & \\
\hline 7 & $\begin{array}{l}\text { When you [target behavior], do you get out of doing things } \\
\text { you didn't want to do? }\end{array}$ & Escape & \\
\hline 8 & $\begin{array}{l}\text { Do you [target behavior] so that people might notice you } \\
\text { more? }\end{array}$ & Attention & \\
\hline 9 & $\begin{array}{l}\text { Do you [target behavior] when you are not allowed to have } \\
\text { a toy or item? }\end{array}$ & Tangible & \\
\hline 10 & Do you like when the teacher talks to you? & Attention & \\
\hline 11 & Is the work assigned too easy for you? & Escape & \\
\hline 12 & $\begin{array}{l}\text { Does anyone ever give you an item you want when you } \\
\text { [target behavior]? }\end{array}$ & Tangible & \\
\hline 13 & $\begin{array}{l}\text { Do you like it when a person takes a toy or item away from } \\
\text { you? }\end{array}$ & Tangible & $\checkmark$ \\
\hline 14 & $\begin{array}{l}\text { Do you get to take a break from work when you [target } \\
\text { behavior]? }\end{array}$ & Escape & \\
\hline 15 & $\begin{array}{l}\text { Do you wish the teacher noticed when you are doing a good } \\
\text { job? }\end{array}$ & Attention & \\
\hline 16 & $\begin{array}{l}\text { Is it helpful when a teacher reminds you a lot to stay on } \\
\text { task? }\end{array}$ & Attention & \\
\hline 17 & $\begin{array}{l}\text { Do you think you'd do better in school if you could play } \\
\text { with something while you work? }\end{array}$ & Tangible & \\
\hline 18 & $\begin{array}{l}\text { Do you think you would do better in school if you got more } \\
\text { help with work? }\end{array}$ & Escape & \\
\hline 19 & $\begin{array}{l}\text { Do you [target behavior] so the teacher will come over and } \\
\text { talk to you? }\end{array}$ & Attention & \\
\hline 20 & $\begin{array}{l}\text { Do you think you should earn more play time for your } \\
\text { work? }\end{array}$ & Tangible & \\
\hline 21 & Do you enjoy your work at school? & Escape & $\checkmark$ \\
\hline 22 & Why do you [target behavior]? & Open-ended & \\
\hline
\end{tabular}


Table 3.

Preference Assessment Items

\begin{tabular}{llc}
\hline$\#$ & Item & Function \\
\hline 1 & Read my work aloud with a teacher & Attention \\
2 & Have a teacher remind me of the rules & Attention \\
3 & Have a teacher tell me to stop or that my behavior isn't nice & Attention \\
4 & Have a teacher tell me good job & Attention \\
5 & Have a teacher watch me while I do work & Attention \\
6 & Work on a tablet instead of paper & Tangible \\
7 & Squeeze a stress ball while I work & Tangible \\
8 & Chew on something while I work & Tangible \\
9 & Keep my hands busy during class & Tangible \\
10 & Hold something soft while I work & Tangible \\
11 & Take a walk outside of the classroom & Escape \\
12 & Do easy work instead of hard work & Escape \\
13 & Take a sitting break at my desk & Escape \\
14 & Choose the work I get to do & Escape \\
15 & Get a no-homework pass & Escape \\
\hline
\end{tabular}


Table 4.

Identified Behavior Functions

\begin{tabular}{lcccc}
\hline Participant & Target Behavior & Student Interview & $\begin{array}{c}\text { Preference } \\
\text { Assessment }\end{array}$ & $\begin{array}{c}\text { Functional } \\
\text { Analysis }\end{array}$ \\
Keith & Off-Topic Speech & Tangible & Attention & Inconclusive \\
Keith & Protesting & Tangible & Tangible & Inconclusive \\
Norbert & Talking Out & Tangible & Tangible & Tangible \& Escape \\
Elias & $\begin{array}{c}\text { Disruptive } \\
\text { Behavior }\end{array}$ & Escape & Escape & Escape
\end{tabular}



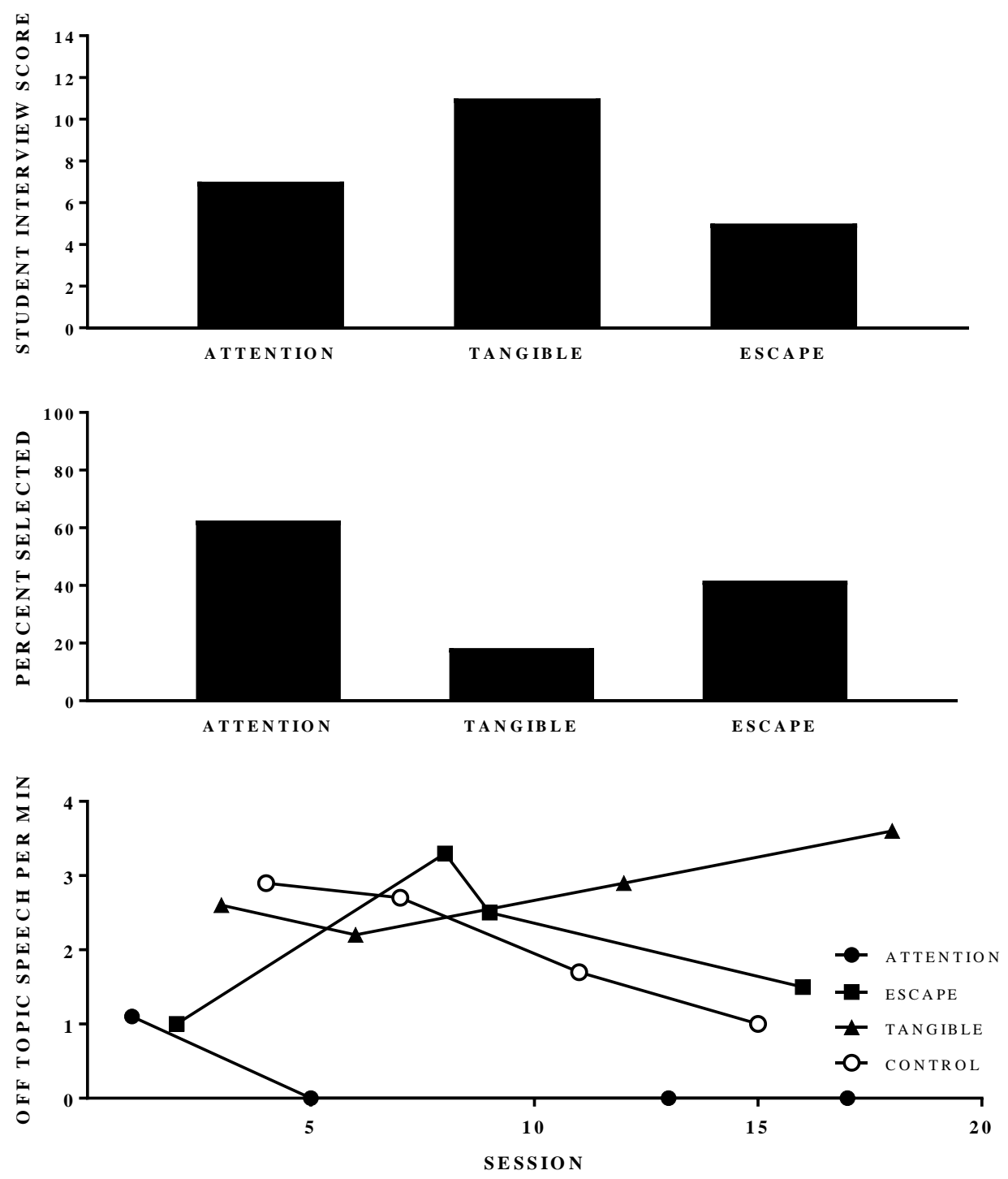

Figure 1. Results from the assessments for Keith's off-topic speech. The top panel shows results from the student interview. The middle panel shows results from the preference assessment. The bottom panel shows results from the functional analysis. 

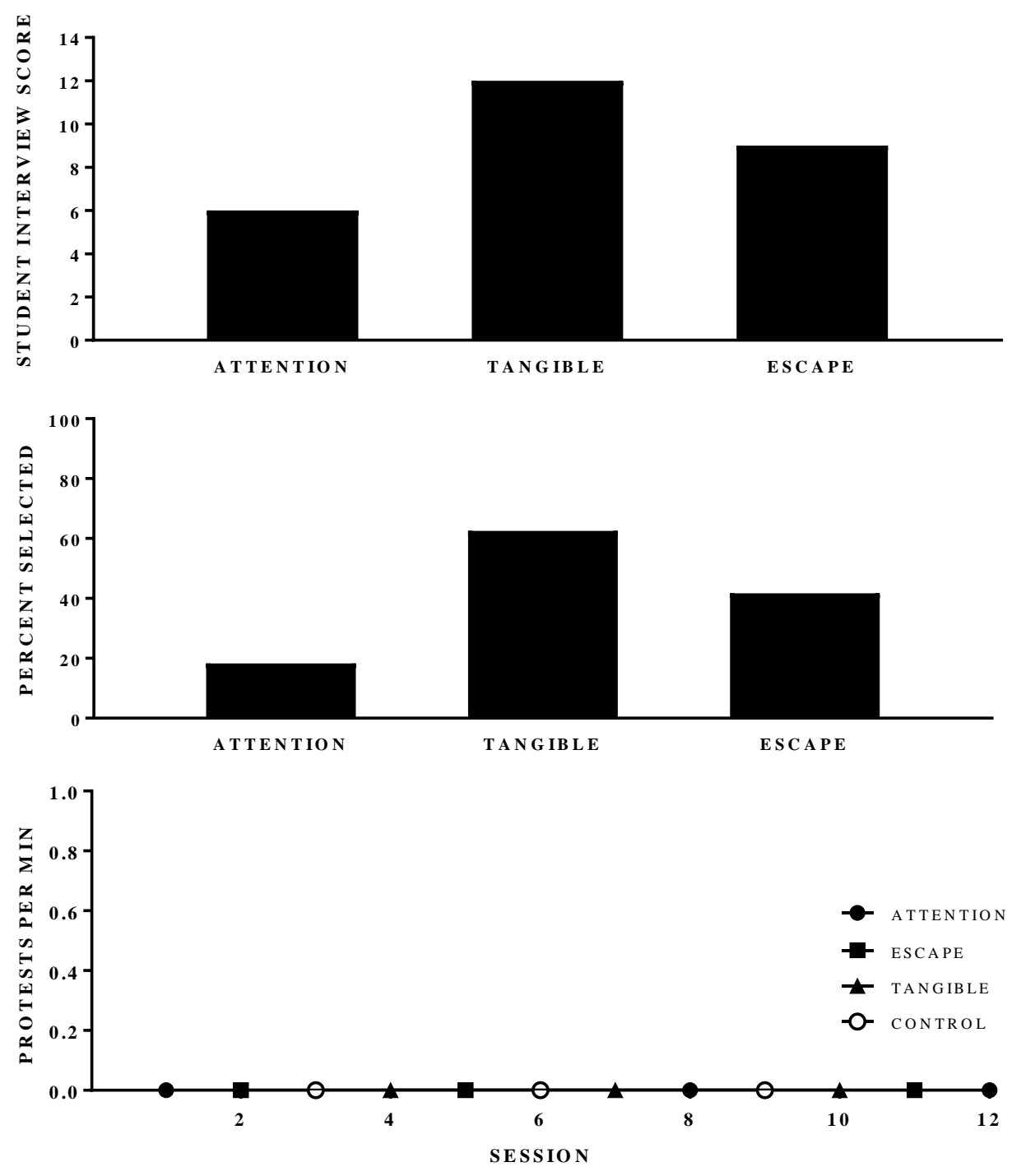

Figure 2. Results from the assessments for Keith's protesting. The top panel shows results from the student interview. The middle panel shows results from the preference assessment. The bottom panel shows results from the functional analysis. 

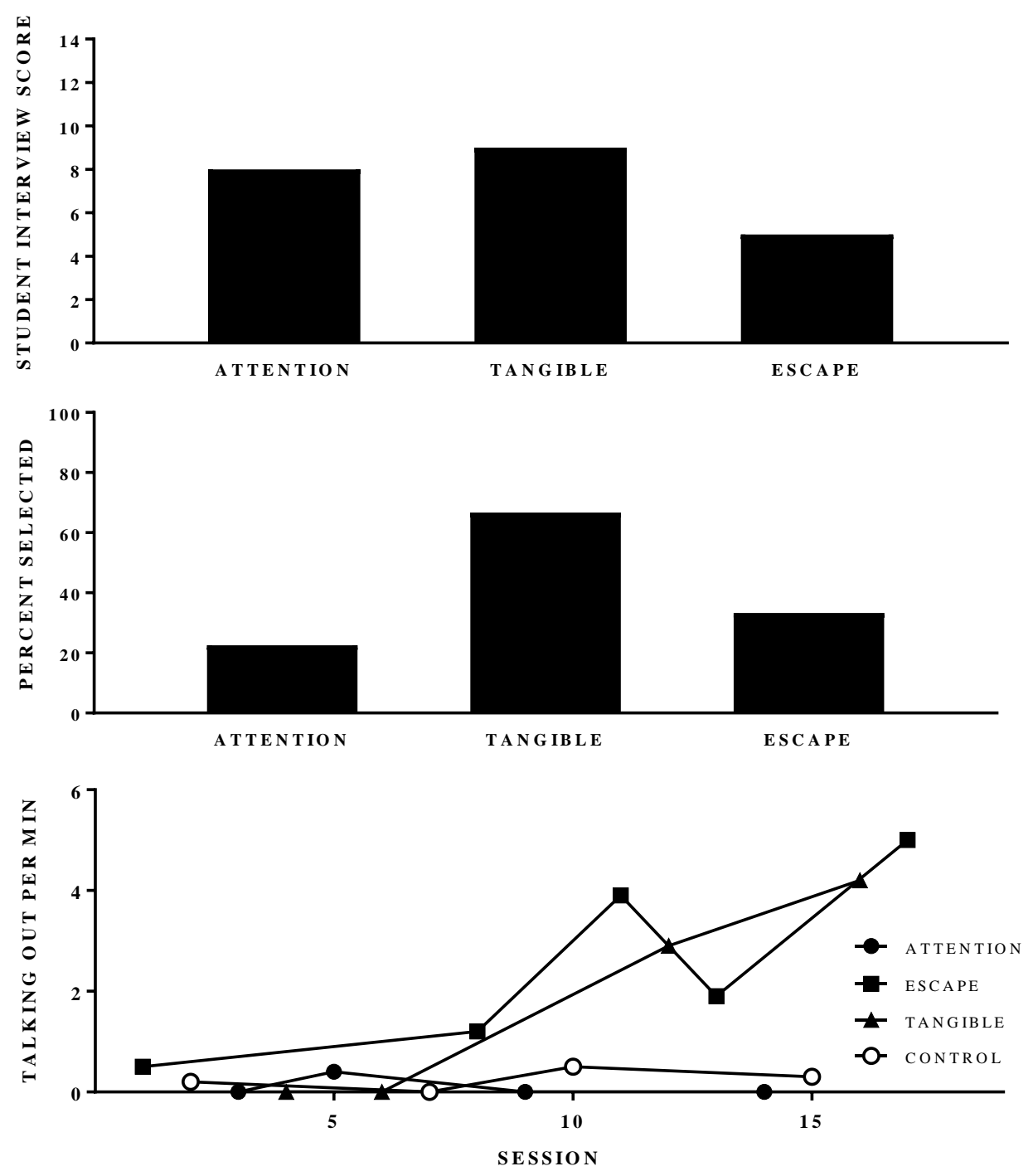

Figure 3. Results from the assessments for Norbert's talking-out behavior. The top panel shows results from the student interview. The middle panel shows results from the preference assessment. The bottom panel shows results from the functional analysis. 

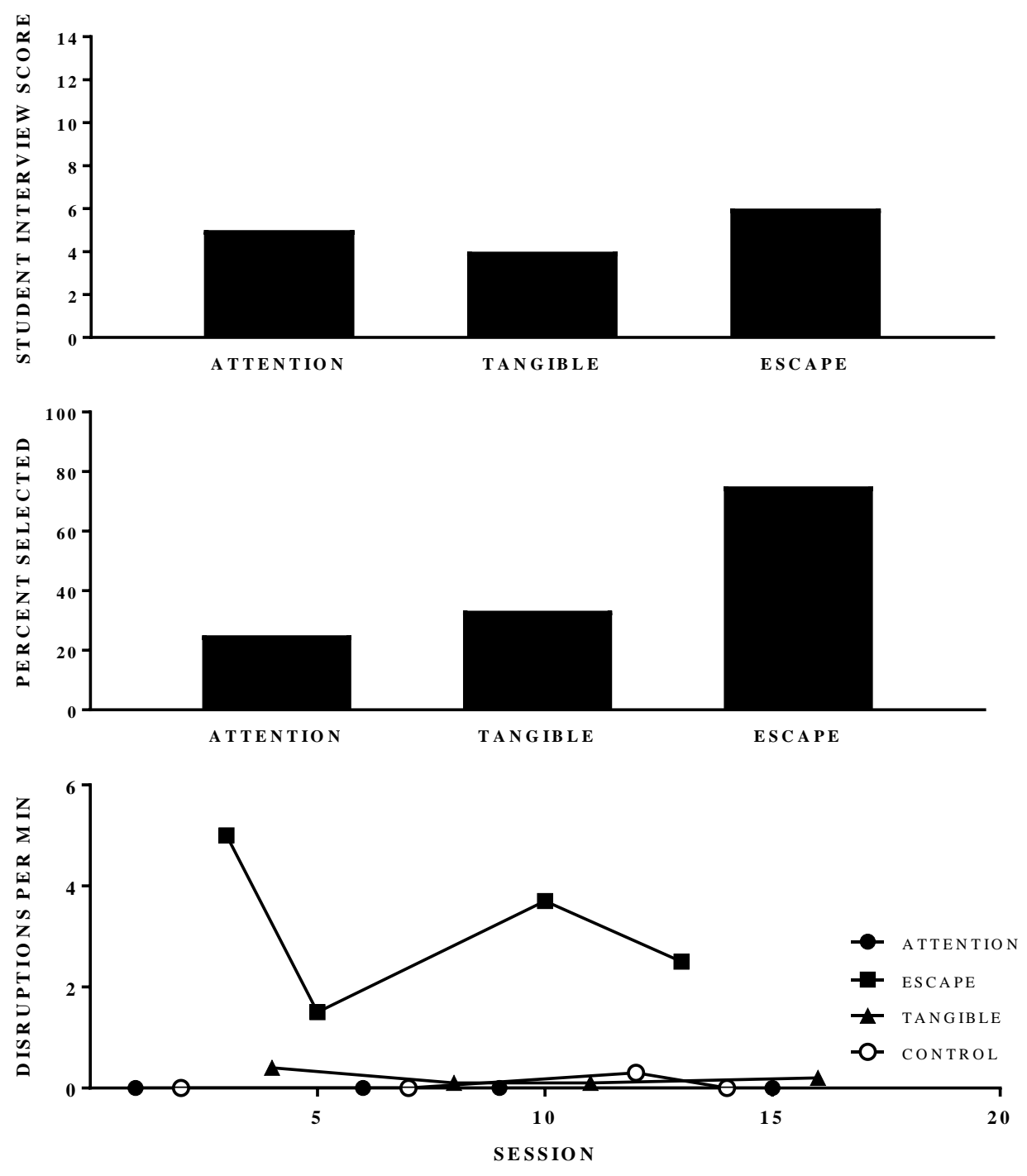

Figure 4. Results from the assessments for Elias's disruptive behavior. The top panel shows results from the student interview. The middle panel shows results from the preference assessment. The bottom panel shows results from the functional analysis. 

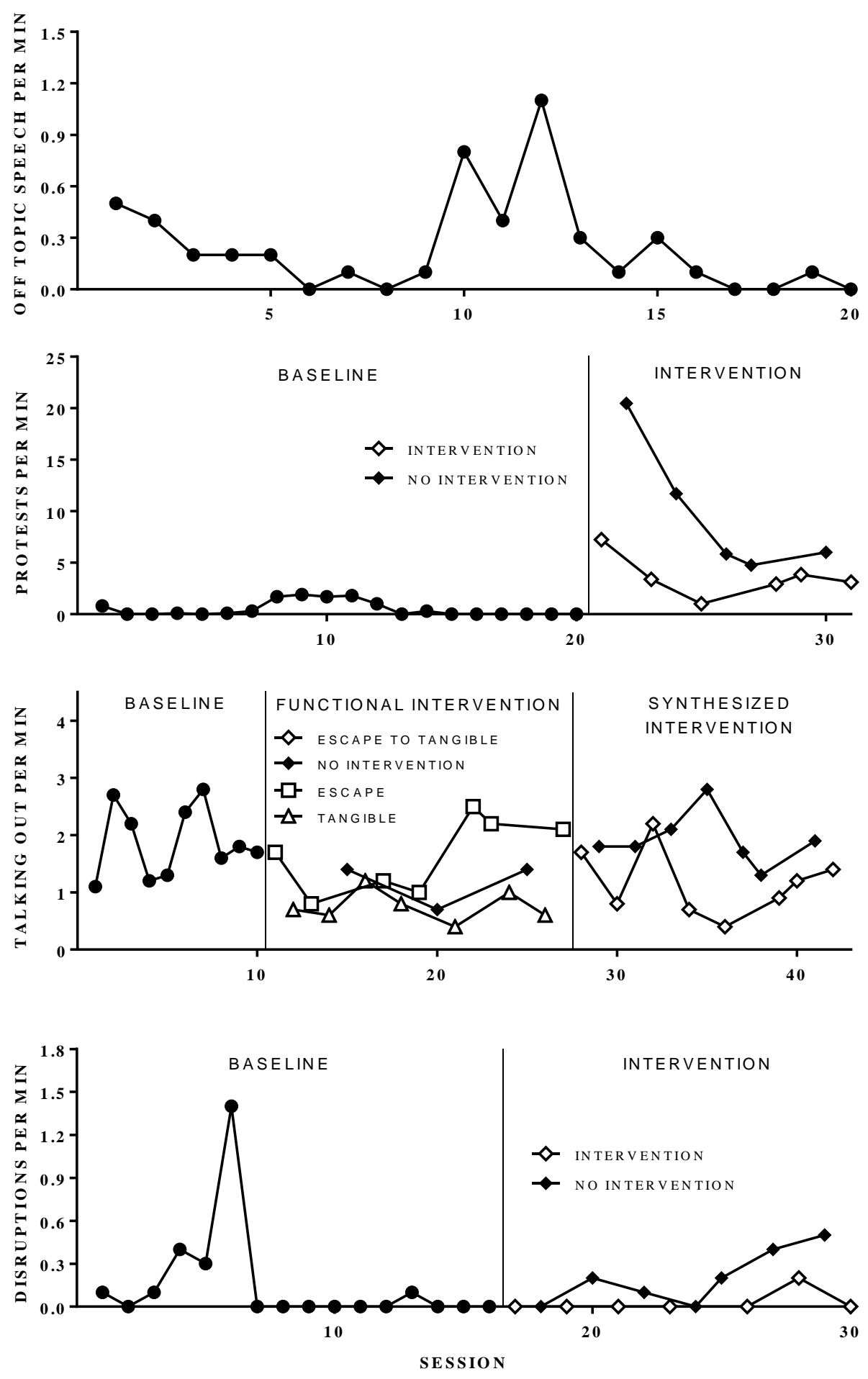

Figure 5. Results from the interventions for all participants and target behaviors. The top panel shows results from Keith's off-topic intervention. The second panel shows results from Keith's protesting intervention. The third panel shows results from Norbert's talking-out interventions. The fourth panel shows results from Elias's disruptive behavior intervention. 
Appendix A.

Student Interview Score Sheet

\begin{tabular}{|c|c|c|c|}
\hline Target Behavior: & Function & $(-)$ & Score \\
\hline 1. Is your work too hard for you? & Escape & & \\
\hline $\begin{array}{l}\text { 2. Do you like it when a teacher notices you when you are } \\
\text { [target behavior]? }\end{array}$ & Attention & & \\
\hline 3. Do you [target behavior] so you can get access to a toy? & Tangible & & \\
\hline 4. Do you feel okay when you're left alone while working? & Attention & $(-)$ & \\
\hline $\begin{array}{l}\text { 5. Do you [target behavior] when a person takes something } \\
\text { away from you? }\end{array}$ & Tangible & & \\
\hline 6. Is it easier to [target behavior] than do your work? & Escape & & \\
\hline $\begin{array}{l}\text { 7. When you [target behavior], do you get out of doing } \\
\text { things you didn't want to do? }\end{array}$ & Escape & & \\
\hline $\begin{array}{l}\text { 8. Do you [target behavior] so that people might notice you } \\
\text { more? }\end{array}$ & Attention & & \\
\hline $\begin{array}{l}\text { 9. Do you [target behavior] when you are not allowed to } \\
\text { have a toy or item? }\end{array}$ & Tangible & & \\
\hline 10. Do you like when the teacher talks to you? & Attention & & \\
\hline 11. Is the work assigned too easy for you? & Escape & & \\
\hline $\begin{array}{l}\text { 12. Does anyone ever give you an item you want when you } \\
\text { [target behavior]? }\end{array}$ & Tangible & & \\
\hline $\begin{array}{l}\text { 13. Do you like it when a person takes a toy or item away } \\
\text { from you? }\end{array}$ & Tangible & $(-)$ & \\
\hline $\begin{array}{l}\text { 14. Do you get to take a break from work when you [target } \\
\text { behavior]? }\end{array}$ & Escape & & \\
\hline $\begin{array}{l}\text { 15. Do you wish the teacher noticed when you are doing a } \\
\text { good job? }\end{array}$ & Attention & & \\
\hline $\begin{array}{l}\text { 16. Is it helpful when a teacher reminds you a lot to stay on } \\
\text { task? }\end{array}$ & Attention & & \\
\hline $\begin{array}{l}\text { 17. Do you think you'd do better in school if you could play } \\
\text { with something while you work? }\end{array}$ & Tangible & & \\
\hline $\begin{array}{l}\text { 18. Do you think you would do better in school if you got to } \\
\text { choose the work you do? }\end{array}$ & Escape & & \\
\hline $\begin{array}{l}\text { 19. Do you [target behavior] so the teacher will come over } \\
\text { and talk to you? }\end{array}$ & Attention & & \\
\hline $\begin{array}{l}\text { 20. Would you like if you could have a stress ball or another } \\
\text { item with you during the day? }\end{array}$ & Tangible & & \\
\hline 21. Do you enjoy your work at school? & Escape & $(-)$ & \\
\hline
\end{tabular}

Scores: Never - 0, Sometimes - 1, Always - 2

* (-) means to invert the score for that item. For example, if "Never" was answered, that would be scored as a 2, and if "Always" was answered, that would be scored as a 0.

Attention:

Escape:

Tangible: 
Appendix B.

Teacher Interview Items

Item

1 What is the target behavior?

2 What does the target behavior look like when it is observed?

3 What are the events that occur immediately before the target behavior is displayed?

$4 \quad$ What are the events that occur immediately after the target behavior is displayed?

5 During which tasks or activities is the target behavior most likely to occur?

6 What time of the day do these tasks or activities typically take place?

7 What are activities that he engages in frequently?

8 What are activities he almost never engages in?

9 What are activities he sometimes engages in?

10 What are his highly preferred tasks?

11 What are his moderately preferred tasks?

12 What are his non-preferred tasks? 
Appendix C.

Keith Off-Topic Speech Preference Assessment Selections
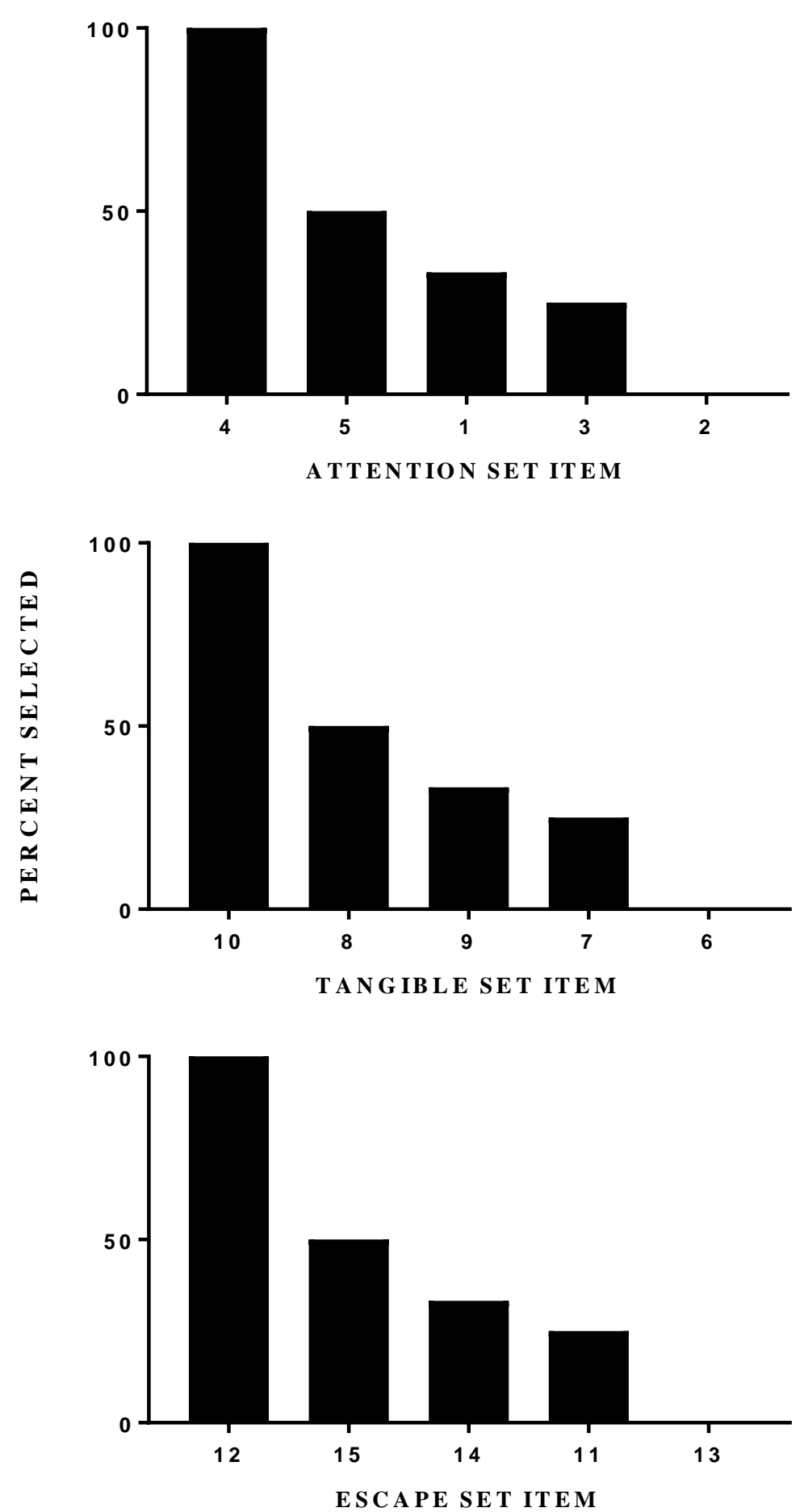

Results from the preference assessments for each functional set (attention, tangible, escape) for Keith's off-topic speech. Refer to Table 3 for item names corresponded with each number. 
Appendix D.

Keith Protesting Preference Assessment Selections
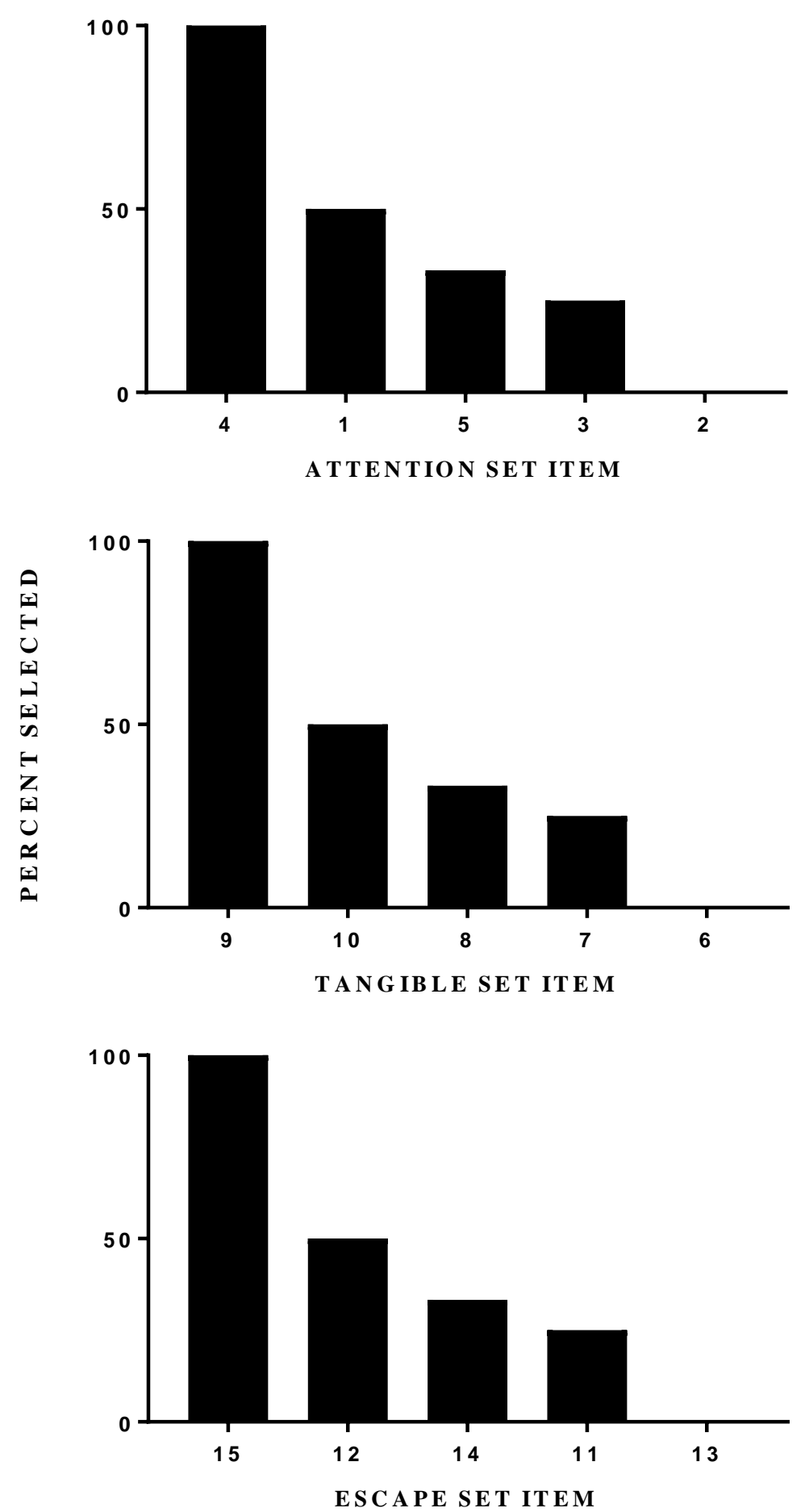

Results from the preference assessments for each functional set (attention, tangible, escape) for Keith's protesting. Refer to Table 3 for item names corresponded with each number. 
Appendix E.

Norbert Talking Out Preference Assessment Selections
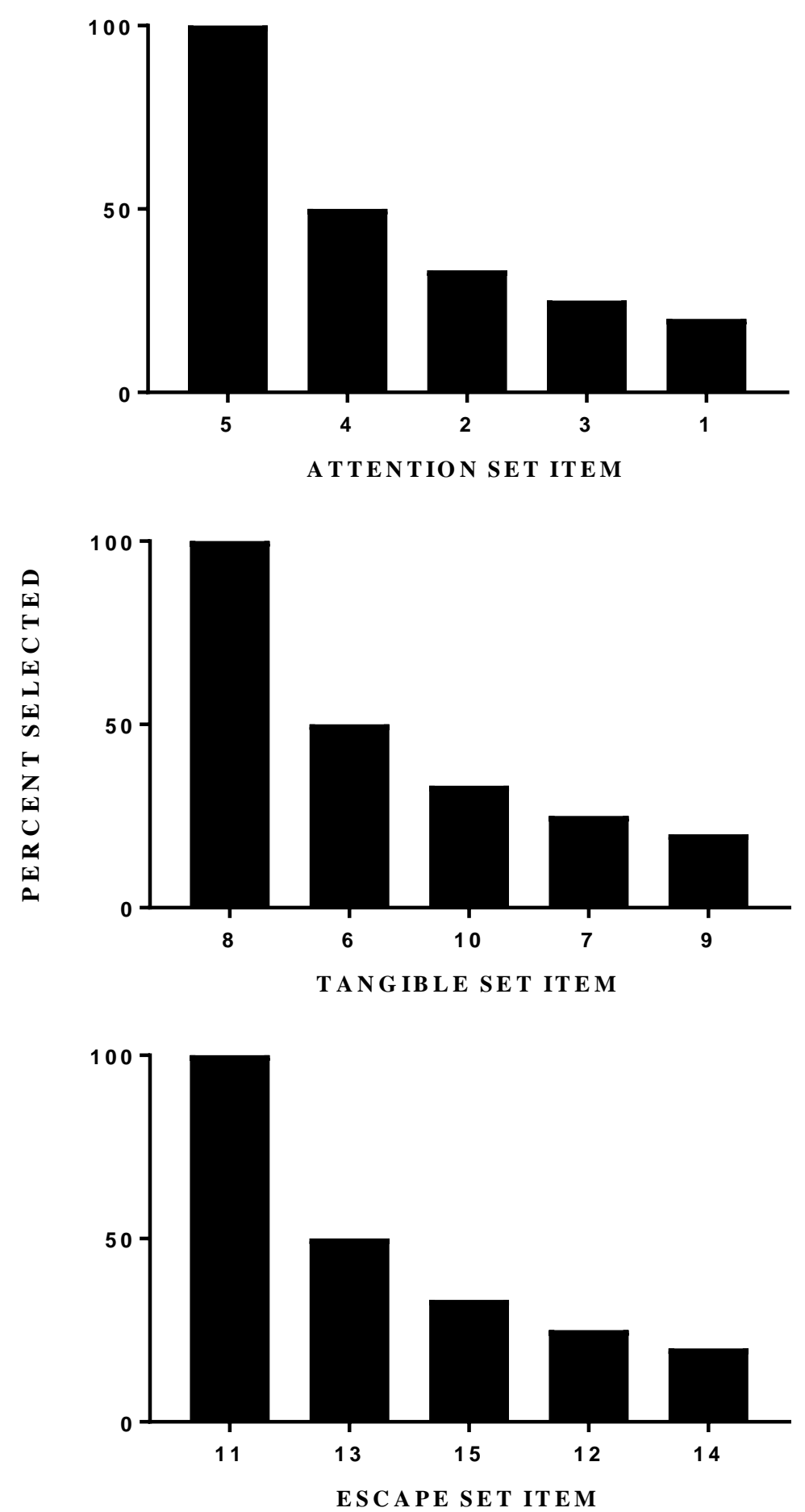

Results from the preference assessments for each functional set (attention, tangible, escape) for Norbert's talking out. Refer to Table 3 for item names corresponded with each number. 
Appendix F.

Elias Disruptive Behavior Preference Assessment Selections
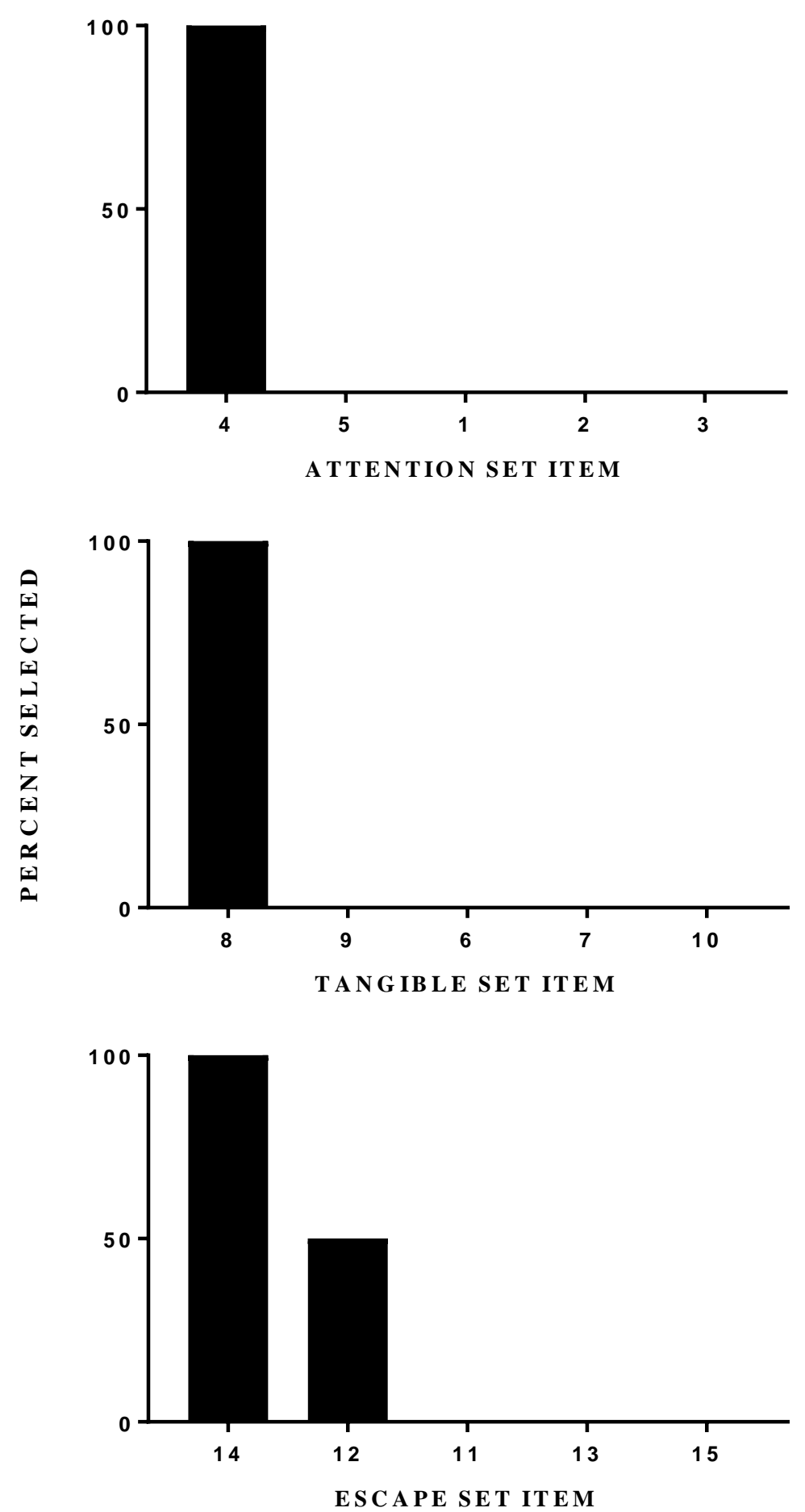

Results from the preference assessments for each functional set (attention, tangible, escape) for Elias's disruptive behavior. Refer to Table 3 for item names corresponded with each number. 